\title{
A description of the global land-surface precipitation data products of the Global Precipitation Climatology Centre with sample applications including centennial (trend) analysis from 1901-present
}

\author{
A. Becker, P. Finger, A. Meyer-Christoffer, B. Rudolf, K. Schamm, U. Schneider, and M. Ziese \\ Global Precipitation Climatology Centre, Deutscher Wetterdienst, Offenbach, Germany \\ Correspondence to: A. Becker (andreas.becker@dwd.de) \\ Received: 31 July 2012 - Published in Earth Syst. Sci. Data Discuss.: 28 September 2012 \\ Revised: 11 January 2013 - Accepted: 31 January 2013 - Published: 21 February 2013
}

\begin{abstract}
The availability of highly accessible and reliable monthly gridded data sets of global land-surface precipitation is a need that was already identified in the mid-1980s when there was a complete lack of globally homogeneous gauge-based precipitation analyses. Since 1989, the Global Precipitation Climatology Centre (GPCC) has built up its unique capacity to assemble, quality assure, and analyse rain gauge data gathered from all over the world. The resulting database has exceeded $200 \mathrm{yr}$ in temporal coverage and has acquired data from more than 85000 stations worldwide. Based on this database, this paper provides the reference publication for the four globally gridded monthly precipitation products of the GPCC, covering a 111-yr analysis period from 1901-present. As required for a reference publication, the content of the product portfolio, as well as the underlying methodologies to process and interpolate are detailed. Moreover, we provide information on the systematic and statistical errors associated with the data products. Finally, sample applications provide potential users of GPCC data products with suitable advice on capabilities and constraints of the gridded data sets. In doing so, the capabilities to access El Niño-Southern Oscillation (ENSO) and North Atlantic Oscillation (NAO) sensitive precipitation regions and to perform trend analyses across the past $110 \mathrm{yr}$ are demonstrated. The four gridded products, i.e. the Climatology (CLIM) V2011, the Full Data Reanalysis (FD) V6, the Monitoring Product (MP) V4, and the First Guess Product (FG), are publicly available on easily accessible latitude/longitude grids encoded in zipped clear text ASCII files for subsequent visualization and download through the GPCC download gate hosted on ftp://ftp.dwd.de/pub/data/gpcc/html/download_gate.html by the Deutscher Wetterdienst (DWD), Offenbach, Germany. Depending on the product, four $\left(0.25^{\circ}, 0.5^{\circ}, 1.0^{\circ}\right.$, $2.5^{\circ}$ for CLIM), three $\left(0.5^{\circ}, 1.0^{\circ}, 2.5^{\circ}\right.$, for FD), two $\left(1.0^{\circ}, 2.5^{\circ}\right.$ for MP) or one $\left(1.0^{\circ}\right.$ for FG) resolution is provided, and for each product a DOI reference is provided allowing for public user access to the products. A preliminary description of the scope of a fifth product - the Homogenized Precipitation Analysis (HOMPRA) - is also provided. Its comprehensive description will be submitted later in an extra paper upon completion of this data product. DOIs of the gridded data sets examined are as follows:
\end{abstract}

doi:10.5676/DWD_GPCC/CLIM_M_V2011_025, doi:10.5676/DWD_GPCC/CLIM_M_V2011_050, doi:10.5676/DWD_GPCC/CLIM_M_V2011_100, doi:10.5676/DWD_GPCC/CLIM_M_V2011_250, doi:10.5676/DWD_GPCC/FD_M_V6_050, doi:10.5676/DWD_GPCC/FD_M_V6_100, doi:10.5676/DWD_GPCC/FD_M_V6_250, doi:10.5676/DWD_GPCC/MP_M_V4_100, doi:10.5676/DWD_GPCC/MP_M_V4_250, doi:10.5676/DWD_GPCC/FG_M_100. 


\section{Introduction}

Precipitation is probably the most important of the essential climate variables (ECVs) identified for the Global Climate Observing System (GCOS; Table 1 in GCOS, 2010). This is mainly due to its crucial role as major source of fresh water in sustaining all formes of life on earth, and its major impact on weather, climate, climate change and related issues of society's adaptation to the latter. The occurrence of precipitation is highly variable in space and time, thus bearing the potential to trigger major flood and drought-related disasters. Finally, high-quality monthly precipitation data sets across a long-term period are key information for an improved understanding of the global water cycle. This need was already identified in the late 1980s by the Commissions for Hydrology and Climatology consulting the World Meteorological Organization (WMO).

In addressing this need, the Global Precipitation Climatology Project (GPCP; WMO, 1990; Adler et al., 2003; Huffman et al., 2009) has been mandated with the development of long-term global gridded records of precipitation for the scientific community in support of the WMO World Climate Research Programme (WCRP) and the Global Energy and Water Cycle Experiment (GEWEX). Naturally, a global data set encompasses both the land surface and the ocean areas of the globe. Noting the limited quality of solely satellitebased quantitative precipitation monitoring across land surfaces due to large biases and stochastic errors (Barret et al., 1994; Rubel and Rudolf, 2001), as well as the potential benefit of gauge-based in situ precipitation measurements across these areas, it was straightforward to design satellitegauge-based data sets. In doing so, the strengths of satellites over oceans are combined with the strength of direct measurements across land surfaces. Supplementary to this approach, regular inter-comparisons of satellite-based precipitation products are made to enhance their reliability. This is coordinated through the International Precipitation Working Group (IPWG; Ebert et al., 2007; Kidd et al., 2010) including the Pilot Evaluation of High Resolution Precipitation Products (Arkin et al., 2005) Project in preparation for the Global Precipitation Measurement (Hou et al., 2008, Chapter 6.4) mission.

From a conceptual point of view, two approaches are possible to construct a high-quality global precipitation satellitegauge reanalysis data set:

i. calibration of satellite data against the in situ data as done for the GPCP project (Huffman et al., 2009), the Climate Prediction Centre (CPC) Merged Analysis of Precipitation (CMAP; Xie and Arkin, 1997) or the Precipitation Reconstruction over Land (Chen et al. , 2002) or

ii. concatenation of data sets according to a resolutiondependent land-sea mask while nudging both data sets along the border (Andersson et al., 2010).

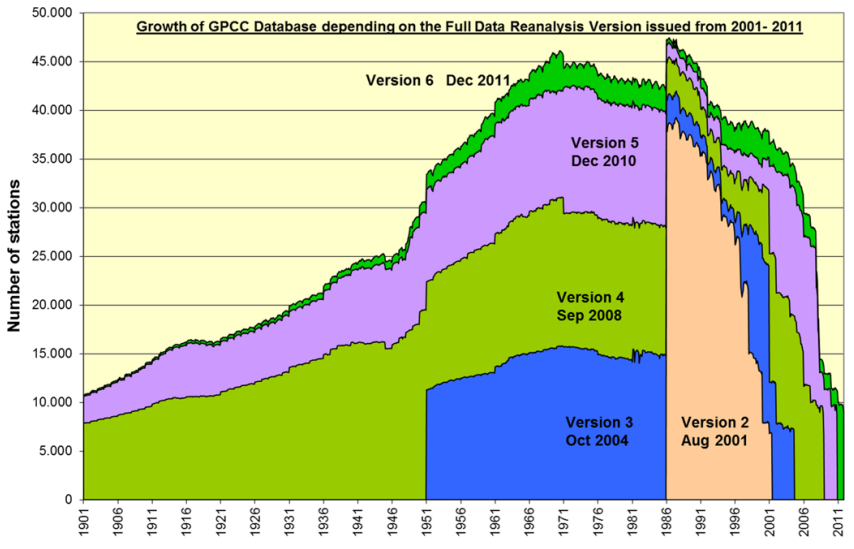

Figure 1. Growth of the GPCC database in terms of number of precipitation gauge stations per data month integrated. Five evolution stages are depicted, concurrent with the dates of issuance of Version 2 (2001), 3 (October 2004), 4 (September 2008), 5 (December 2010) and 6 (December 2011) of the Full Data Reanalysis. The ticks denote the Januaries of each year.

Approach (i) yields an optimum spatial homogeneity of the data set without jumps along the coastlines. The coastlines separate the oceanic regime with satellite-only data from the land surface area where both kinds of data are available. For approach (ii), a nudging scheme is required to make up for potential jumps along the coastline. On the other hand, it utilizes only one data source per regime, which allows for a more reliable diagnosis of the systematic (measurement device specific) error for the oceanic (satellite-based) and the land surface (gauge-based) precipitation analysis.

Regardless of the approach chosen, there is a strong demand for high-quality rain-gauge-based precipitation reanalysis data sets to serve the in situ based reference component for the period also covered by satellite data (Kidd et al., 2012; Kidd and Huffman, 2011). In 1988 the Deutscher Wetterdienst volunteered to provide such a data set, and was mandated to do so by the WMO World Climate Research Programme (WCRP). The Global Precipitation Climatology Centre was inaugurated at Deutscher Wetterdienst in 1989, but it took several more years to provide the first land surface precipitation analysis product, a decadal data set (19861995 ) in contribution to GEWEX of WCRP (Rudolf, 1995). The series has been extended backwards to 1979 by another preliminary gauge product using the same analysis method but a less dense network (Xie et al., 1996).

In parallel with these settlements, Global Precipitation Climatology Centre (GPCC) has successively extended the temporal coverage of its analysis products backward from present to 1901 (see also Fig. 1). For earlier years the number of available data stations is too small to support a reliable analysis.

Since 2008, the GPCC has introduced the anomaly interpolation method for all its re-processing products while utilizing for the analysis of the climatology background field the 
entire database of stations recruited from all sources listed in Sect. 2.2. The method has been tested by the GPCC for the first time during the VASClimO project (Beck et al., 2005). It interpolates the anomalies against a background climatology field with subsequent superposition of the yielded anomaly field to the background instead of interpolation of the absolute precipitation totals. The method takes advantage of the fact that the station network supporting the climatology is usually much larger than the network of stations actually available for the specific month analysed, thus reducing the sampling error in particular for undersampled months and regions.

Of course, the GPCC portfolio of gridded global data sets of monthly terrestrial precipitation based on gauge data was and is not unique as such. There have been similar data archives and products compiled and published by the Climate Research Unit (CRU) of the University of East Anglia (New et al., 1999, 2000, 2001, 2002); by Peterson and Vose (1997) and Peterson et al. (1998) based on the Global Historical Climatology Network (GHCN) data set, by Hijmans et al. (2005), and by Mitchell and Jones (2005), all for a number of atmospheric ECVs including precipitation. For precipitation only, there are also the data sets published by Dai et al. (1997) and Matsuura and Willmott (2012). A strength of some of these data sets lies in the public availability of both the gridded products and the underlying original station observations. This is in distinct contrast to the GPCC data products where the latter cannot be provided for many stations as GPCC does not claim copyrights on acquired data, which is also true for the non-global "APHRODITE's Water Resources" data sets published by Yatagai et al. (2009, 2012). Therefore, GPCC applies a general policy not to parse any original station data but to pass according requests to the original suppliers, if possible. On the other hand, the GPCC data archive is by far the largest worldwide for monthly precipitation, outperforming the global precipitation data coverage of all aforementioned data sets by at least a factor of two and partly much more. The non-claiming of copyrights on the original data is certainly a key to this success. In line with the scope of the ESSD journal, this paper serves as a reference publication to describe the multi-decadal and partly centennial data products published by the GPCC. The five products are the following:

\section{a. GPCC - Climatology (CLIM) Version 2011} (Meyer-Christoffer et al., 2011a-d)

Target period 1951-2000, with the grid resolution specific DOIs

doi:10.5676/DWD_GPCC/CLIM_M_V2011_025

(for $0.25^{\circ}$ ),

doi:10.5676/DWD_GPCC/CLIM_M_V2011_050

(for $0.5^{\circ}$ ),
doi:10.5676/DWD_GPCC/CLIM_M_V2011_100

(for $1.0^{\circ}$ ), and

doi:10.5676/DWD_GPCC/CLIM_M_V2011_250

(for $2.5^{\circ}$ ) jointly referring to ftp://ftp.dwd.de/pub/data/

gpcc/html/gpcc_normals_v2011_doi_download.html

b. GPCC - Full Data Reanalysis (FD) Version 6.0

(Schneider et al., 2011c-e)

Period 1901-2010 with the grid resolution specific DOIs

doi:10.5676/DWD_GPCC/FD_M_V6_050 (for 0.5 ${ }^{\circ}$ ), doi:10.5676/DWD_GPCC/FD_M_V6_100 (for 1.0 $0^{\circ}$, and

doi:10.5676/DWD_GPCC/FD_M_V6_250

(for $2.5^{\circ}$ ), jointly referring to ftp://ftp.dwd.de/pub/data/ gpcc/html/fulldata_v6_doi_download.html

c. GPCC - Monitoring Product (MP) Version 4.0

(Schneider et al., 2011a, b)

Period 2007-present in Version 4 (in Version 1 since 1986) with the resolution specific DOIs

doi:10.5676/DWD_GPCC/MP_M_V4_100 (for 1.0º) and

doi:10.5676/DWD_GPCC/MP_M_V4_250 (for 2.5 $5^{\circ}$ ) jointly referring to ftp://ftp.dwd.de/pub/data/gpcc/html/ gpcc_monitoring_v4_doi_download.html

d. GPCC - First Guess Product (FG) (Ziese et al., 2011)

Period August 2004-present (temporally inhomogeneous due to version changes)

doi:10.5676/DWD_GPCC/FG_M_100 (for 1.0 $0^{\circ}$ )

referring to ftp://ftp.dwd.de/pub/data/gpcc/html/gpcc firstguess_doi_download.html

\section{e. GPCC - Homogenized Precipitation Analysis (HOMPRA) Version 1.0}

Period 1951-2005 (fully homogeneous, replaces VASClimO V1.1)

Tentative DOIs

10.5676/DWD_GPCC/HOM_M_V1_<xxx $>$ with $\mathrm{xxx}=050,100$ and 250 depending on the resolution, similar to the Full Data (FD) product.

The fifth product, the Homogenized Precipitation Analysis (HOMPRA) product, being the follower of the VASClimO product published by Beck et al. (2005) and still available from ftp://ftp.dwd.de/pub/data/gpcc/vasclimo/, could not be completed before submission of this paper. Therefore, only basic features will be described here (Sect. 7.4), while a thorough description will be published in a follow-up paper corresponding to the release of HOMPRA. 
Data Sources Utilized

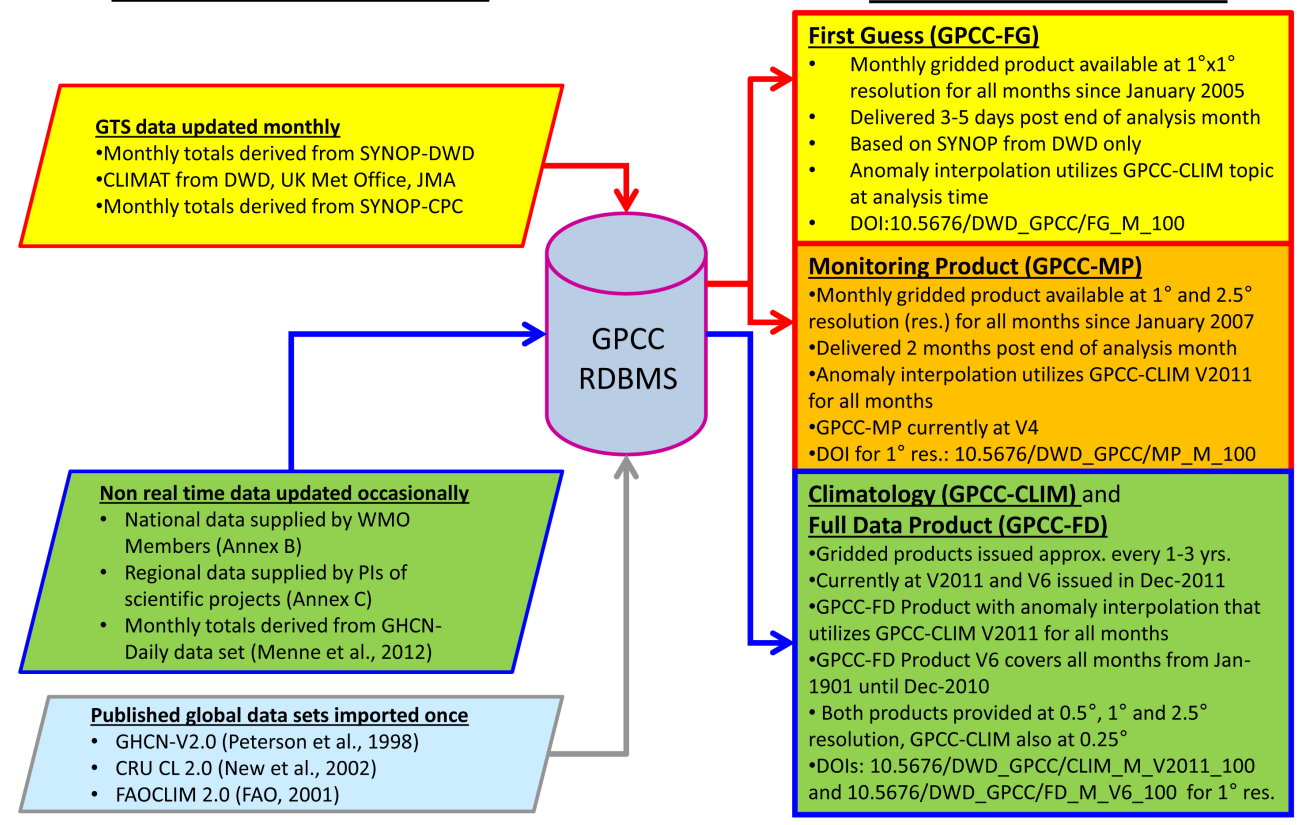

Figure 2. Overview graph of the data sets and sources (left-hand side) utilized by GPCC to feed its relational database management system (RDBMS), serving as input for the DOI-referenced gridded GPCC data products specified on the right-hand side. Red (blue) framed and coloured objects relate to sources and products acquired and processed in near (non-) real-time mode.

The release of the DOI references implies that ISO 19115 compliant metadata are provided under web addresses constructed from the DOI proceeded by http://data.datacite.org. For example, the metadata for the "GPCC Climatology Version 2011 " at $0.25^{\circ}$ resolution are available from http://data. datacite.org/10.5676/DWD_GPCC/CLIM_M_V2011_025.

Figure 2 gives an overview of the DOI-referenced GPCC products including their underlying database and sources. These products are also included in the data set catalogue of the Climate Data Centre (CDC) of Deutscher Wetterdienst (DWD), which disseminates ISO 19139 compliant metadata on its data sets through the GeoNetwork software application. For example the GPCC Climatology Version 2011 products are documented under http://cdc.dwd.de/catalogue/srv/de/main.home?uuid=de. dwd.gpcc.dataset.monthly.climatology.version 2011.

In this GPCC reference paper, the underlying database and provenance is described thoroughly in Sect. 2, followed by brief descriptions of the data quality control (QC) applied to the station data in Sect. 3. The QC issues will be elaborated in a companion paper of Schneider et al. (2013). Here, we will focus on the description of the gridded GPCC products in terms of the specific methodologies applied for the gridding of the station data in Sect. 4, the additional information available with regard to the uncertainty of the products, and a comparison of the three interpolation methods (arithmetic mean, modified SPHEREMAP - Willmott et al., 1985, and ordinary kriging - Rubel and Hantel, 2001) and their related sampling errors (Sect. 5). As will be explained in Sect. 5.2, GPCC chooses SPHEREMAP for its monthly products. For the daily products, however, currently under development at GPCC, the issue of undersampling and intermittency is more severe, and the performance of ordinary kriging is tested again. Daily GPCC products are not part of this paper, but will be discussed in a separate paper upon their first release.

Section 6 will describe how the GPCC Climatology is constructed, which is important information as it serves the background field for the other GPCC analysis products described in Sect. 7 together with sample applications to resolve El Niño-Southern Oscillation (ENSO)- and North Atlantic Oscillation (NAO)-related precipitation patterns and to reveal trends in precipitation across the past century. Finally, Sect. 8 informs on access methods to the data sets and provides basic user advice.

\section{GPCC's rain gauge database}

The accuracy of rain-gauge-based precipitation analyses mainly depends on the spatial density of stations being used. For example, in order to calculate monthly area-mean precipitation on a $2.5^{\circ} \times 2.5^{\circ}$ grid with a sampling error of less than $10 \%$, the accuracy requirement of the GPCP (WMO, 1990), it takes 8 to 16 stations per grid cell depending on the variability of the precipitation in the region analysed (Jenne and Joseph, 1985; Rudolf et al., 1994). This corresponds to a global requirement of 40000 homogeneously distributed stations. 
The rain gauge data received so far by GPCC can be divided into the part received in near real-time (Sect. 2.1) through the Global Telecommunication System (GTS) and the much larger part collected offline (Sect. 2.2). In total, data from more than 85000 stations have been integrated at least once throughout the centennial reanalysis period starting in 1901. This is a good success rate of $57 \%$ or $34 \%$ of the total number of gauges operated worldwide being 150000 according to New et al. (2001) or 250000 according to Strangeways (2007). However, the GPCC applies a 10-yr minimum constraint with regard to the duration of the longest uninterrupted time series at each station as a screening criterion for the cadre data set of the background climatology GPCCCLIM. Therefore, the number of stations utilized for GPCCCLIM is exactly 67298 (67 149) stations for the best (worst) covered month June (December). 65335 stations pass the 10 -yr constraint for every month of the year and are therefore utilized for the annual climatology. Further details on the GPCC-CLIM construction will be presented in Sect. 6 .

\subsection{Near real-time GTS database}

A subset of about 8000 of the 12000 stations listed in WMO Volume A (WMO, 2011a) is currently internationally exchanged between the National Hydro- and Meteorological Services (NHMSs) through the GTS on a regular basis. Monthly precipitation data from the following three sources are routinely obtained at GPCC within about one month after observation, and can thus be used for the early analyses.

\subsubsection{Meteorological synoptic data (SYNOP) received at DWD, Offenbach}

The SYNOP data received at DWD form the primary GTS source. Its primary purpose is the analysis of current global weather charts and the initialization of numerical weather prediction models. For GPCC purposes, only the precipitation-related components of the SYNOP code are evaluated as follows:

- the precipitation group: $t_{\mathrm{R}} \mathrm{RRR}$ with $t_{\mathrm{R}}=$ time interval $\left(t_{\mathrm{R}}\right.$ can be $1 \mathrm{~h}, 3,6,12,18$ or $\left.24 \mathrm{~h}\right)$ and $\mathrm{RRR}=$ precipitation total for the interval $t_{\mathrm{R}}$ in $\mathrm{mm}$, respectively in tenths of $\mathrm{mm}$ for precipitation amounts less than $1 \mathrm{~mm}(\mathrm{RRR} \geq 990)$;

- the weather group wwWW, where ww and WW describe the observed current weather (e.g. $\mathrm{ww}=65$ : heavy rainfall) and the past weather; and

- the climatological precipitation group RRRR with $R R R R=$ precipitation total for the last $24 \mathrm{~h}$.

The limited number of GTS stations makes their data particularly precious so the GPCC data processing routine includes some automatic quality checks and corrections to rescue damaged SYNOP messages:
- correction of obvious coding errors;

- consistency check of $t_{\mathrm{R}} \mathrm{RRR}$ for messages overlapping in time;

- plausibility check of RRR with respect to typical maximum values;

- consistency check of RRR versus ww and WW; and

- completion of missing $t_{\mathrm{R}} \mathrm{RRR}$ messages by $t_{\mathrm{R}} 000$ in case of available weather groups messages indicating no precipitation for the corresponding time interval $t_{\mathrm{R}}$.

For months featuring $100 \%$ SYNOP data availability, the monthly precipitation totals can be easily calculated. However, this is on average only the case for about 2000 of 6800 SYNOP stations. The other stations feature incomplete monthly data availabilities with smaller or larger data gaps. Based on statistical inter-comparison studies (Schneider et al., 1992), the application of a $70 \%$ minimum availability (Pct) constraint yields an acceptable reliability of the monthly total $P_{\mathrm{M}}$ calculated by

$P_{\mathrm{M}}=R_{\text {Sum }} \cdot \frac{100 \%}{\text { Pct }}$,

where $R_{\text {Sum }}$ is the sum of the observed precipitation intervals with Pct $\geq 70 \%$ during the month regarded, keeping the mean difference between the monthly totals calculated as under Eq. (1) and reference data (CLIMAT, see next section) at about $15 \%$ of the reference. With further decreasing data availability, this deviation would increase. All SYNOP-based monthly totals calculated by the GPCC are accompanied by quality indices representing the availability and corrections of individual SYNOP stations.

\subsubsection{Monthly CLIMAT reports received at DWD, Japan Meteorological Agency and UK Met Office}

In the framework of the regulated global data exchange, monthly climatic data for more than 2000 stations are disseminated by the countries via GTS as CLIMAT bulletins. The CLIMAT bulletins include monthly means or totals for a number of variables compiled from reprocessed SYNOP observations collected by the publisher. The data are known to be of high quality, because some control of quality and completeness was performed on them. However, some errors may still occur, partly caused by the manual coding process. Therefore, the data are checked by GPCC upon arrival for typical coding errors, completeness and consistency. The plausibility of monthly precipitation is examined using additional information that is also part of the CLIMAT bulletin, e.g. number of days with precipitation above $1 \mathrm{~mm}$ and the quintile of the monthly data with regard to the frequency distribution, yielding the possibility to recognize and flag questionable data. The resulting quality-controlled CLIMAT precipitation data serve as reference data during GPCC's QC 


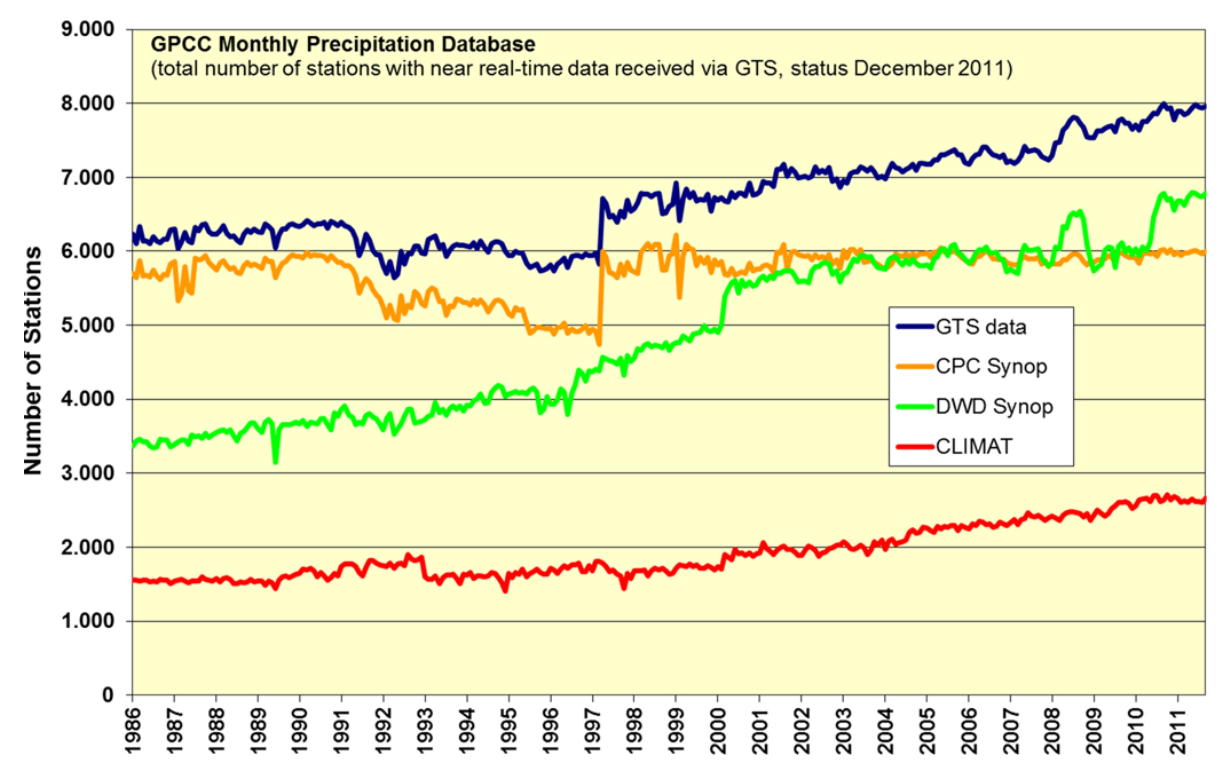

Figure 3. Total number of unique stations (blue line) received via GTS from 1986 until 2011 when more than 8000 stations reached GPCC. In addition the three sources forming the total (CPC- and DWD-SYNOP and CLIMAT) are also depicted by orange, green and red lines.

procedures explained in much more detail by Schneider et al. (2013).

\subsubsection{Monthly precipitation derived from SYNOP data, the global 40000 collected by NOAA/CPC}

As a third source, GPCC utilizes the monthly precipitation data of the Climate Prediction Center (CPC), Washington DC, hosted by the National Oceanic and Atmospheric Administration (NOAA), which is mainly based on SYNOP data. The global SYNOP data collection received by CPC through the GTS does not fully overlap the collection received at Offenbach, and thus features unique data contributions. While the CPC receives more data for the Americas, Eastern Russia and some African regions, the DWD reaches a much higher data density over Europe. The CPC procedure to estimate monthly precipitation totals and especially to fill gaps in the SYNOP precipitation series is different from the GPCC method described before. In addition to GPCC's method, CPC includes precipitation data being statistically estimated from the qualitative weather observations ww and WW, and extrapolates to the full month even if only relatively few observations are available. Therefore, GPCC ranks redundant CPC-SYNOP below the DWD ones but still applies cross-checking of both data to detect trivial data transmission or encoding/decoding errors.

In order to obtain the best possible spatial data coverage at the earliest time as required by the GPCP and other users, the GPCC merges for its Monitoring Product the monthly totals from all three GTS data sources CLIMAT, DWD-SYNOP and CPC (Fig. 3) after each of them has been loaded into GPCC's relational database management system (RDBMS).
From this database it is subsequently made available for the monthly near real-time GPCC Monitoring Product and other analyses.

The near real-time database provides, in some regions, a sufficient database for quantitative precipitation estimates, if the grid resolution is not too high. Therefore, the GTS-based GPCC products are only offered on $2.5^{\circ}$ and $1.0^{\circ}$ resolving latitude/longitude grids but not at $0.5^{\circ}$ in contrast to the reanalysis products utilizing also non-GTS data. Moreover, the number of stations per grid is provided as additional information to every GPCC product, to allow for an easy assessment of its potential reliability.

Within the data pool, the CLIMAT data - after a quality check - are assigned a higher quality and provide therefore a reference for quality assessment of the SYNOP-based data. The earliest GPCC (First Guess) product is publicly available for all months since August 2004 and utilizes only the DWD SYNOP-based monthly precipitation totals from approximately 6000 stations (Fig. 3). Most recently this number has increased to more than 6800 stations. For the GPCC Monitoring Product (issued two months later than the corresponding First Guess Product), almost 8000 stations are utilized nowadays starting from approximately 6000 GTS stations in 1986.

\subsection{GPCC full database}

All other data not exchanged through the GTS have been originally raised by WMO NHMSs for the specific purposes of the host countries, and their exchange is subdued to particular national rules. There remain only a few NHMSs who publish their national data without restrictions or with 


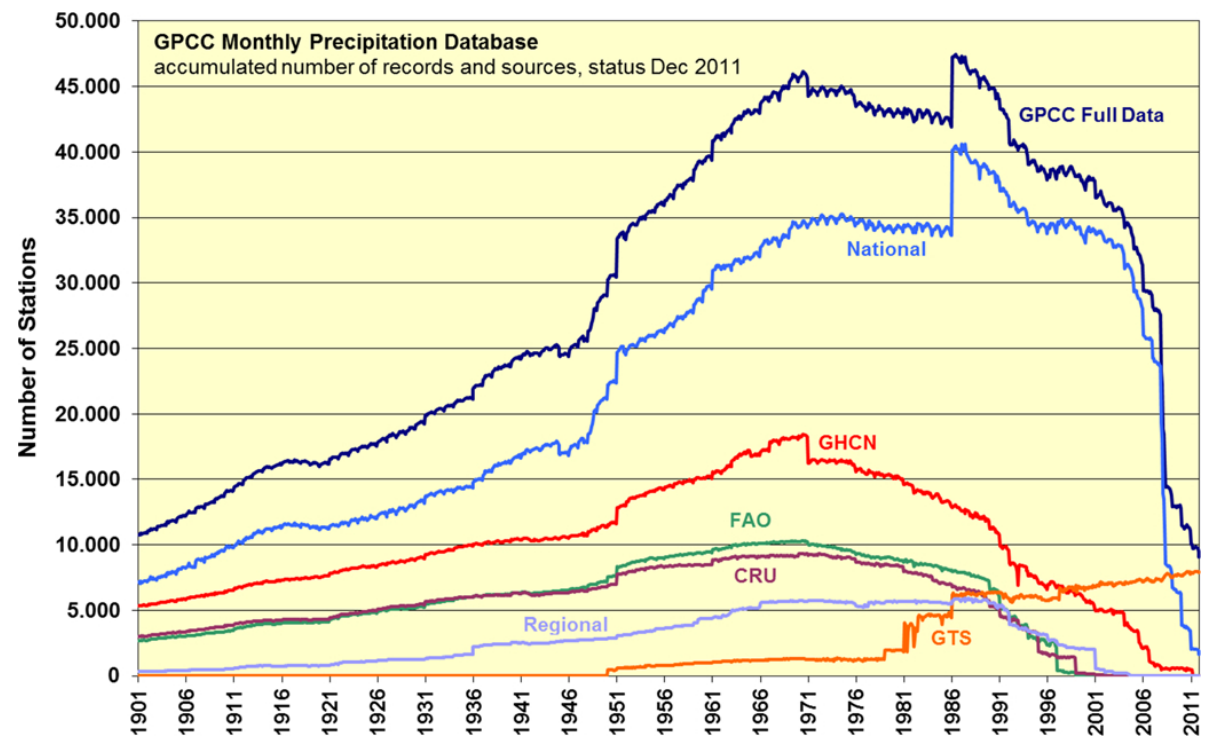

Figure 4. Number of monthly precipitation data in the GPCC database as a function of time across the periods covered by GPCC products for the GTS-based and the five different historical data sources in the GPCC database. Moreover, the total number of unique stations (dark blue line) is shown. The ticks denote the Januaries of the years.

copyrights through the Web. Therefore, GPCC needs to perform data acquisition in order to access the many more stations that are not reporting through the GTS. Major sources include the following:

1. national data contributions by WMO Members (158 countries and 31 regional suppliers, thus for bringing the number of national sources to 189; see Appendix B);

2. data collections of some international regional projects (e.g. SE Asia, Africa, former Soviet Union);

3. global data collection (approx. 11800 stations) of the Climate Research Unit (CRU, Norwich, UK; New et al., 2002);

4. global data collection (approx. 13500 stations) of the UN Food and Agriculture Organization, (FAOClim 2.0,2001); and

5. collection (approx. 34800 stations) of the Global Historical Climatology Network (GHCN) at NCDC, Asheville, USA. It is a composite of the GHCN-V.2, data set (Peterson and Vose, 1997; Peterson et al., 1998; approx. 20600 stations) permanently supplemented by monthly totals calculated from the GHCN-daily data set (Menne et al., 2012).

National data contributions are normally acquired through bilateral correspondence of GPCC with the responsible national agencies. Moreover, all WMO Members are informed by circular letters of WMO about the international task of the GPCC and the corresponding data requirements. The GPCC has funds neither for data purchasing nor for covering any shipping costs. The data delivered are contributions of the countries to the international task of the GPCC and are restricted to the defined purpose. Notably many countries of the world still do not grant copyrights on their data putting GPCC into the dilemma to either issue products with full data access but large areas on the global map being basically unmonitored or to respect the copyrights of every data supplier and to publish only gridded products from the data, but not the original data itself. GPCC choose the latter which can be criticized as contradicting open access data policies. Nevertheless, it has yielded a database of double and triple size (Fig. 4), respectively, with regard to the most popular data sets of the GHCN (Peterson and Vose, 1997; Peterson et al., 1998) and the Climate Research Unit (CRU) of the University of East Anglia (New et al., 2002) that supply the original data to the community but actually feature unmonitored areas. In order to warrant transparency on our methods without parsing data to third parties, any scientist is invited to inspect the GPCC archive and its methods on site at the Headquarters of the Deutscher Wetterdienst. Moreover, GPCC invites all past and future suppliers of data to waive the copyrights on their data to ultimately serve the community a global product with both best data coverage and full data access.

Original data are provided from a national source (i) and originate from the institution (e.g. a WMO NMHS) that carried out the measurements. This constitutes the core part of the GPCC database (Fig. 4). To be comprehensive in its approach, the GPCC integrates other global precipitation data collections from sources (iii) to (v) as well as several regional data sets. For example, a data set from Nicholson (1979) comprising unique precipitation data across Africa has been 


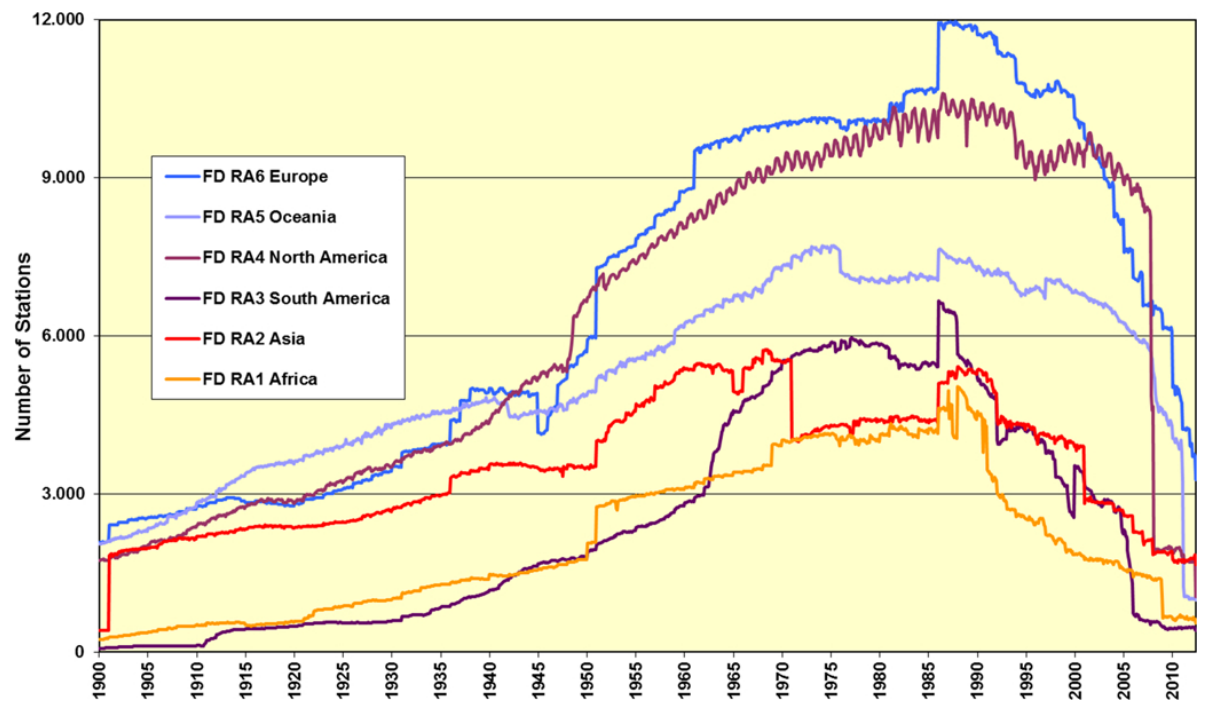

Figure 5. Number of rain gauges (coloured lines) supplying monthly precipitation data in the GPCC database as a function of time across the periods covered by GPCC products for the six different regions defined by the WMO regional associations (RAs). Consult http://www. wmo-dra.info/gmap/WMO_NMHS_regions/metservices.html for a map of the RAs.

integrated in 2010, as well as an update of the data set of Pavel ("Pasha") Groisman (NCDC, 2005) for the countries of the former Soviet Union. As a result of these efforts, the GPCC holds the largest and most comprehensive collection of monthly precipitation data worldwide, which is continuously updated and extended.

All precipitation data received are stored in source-specific slots within the RDBMS, and the corresponding metainformation and quality indices are assigned to the data. The eight aforementioned major sources (CLIMAT, DWDSYNOP, CPC-SYNOP, National, Regional, CRU, FAO and GHCN) are considered.

Figure 4 displays the temporal evolution of the number of monthly precipitation station data in the GPCC database from the different sources during the time period 1901-2011. The volume and up-to-dateness of the individual data provisions largely differ, with the time delay resulting in an increase of the number of stations being available for the analyses looking back from year 2011, where basically the GTS coverage determines the total number of available stations until the month of best data coverage, i.e. June 1986 with monthly precipitation data being available for just 47400 stations. Looking further into the past, there is a drop from 47228 stations in January 1986 to 41285 in December 1985 with an increase further backward until another local maximum of 45869 stations for June 1970. This drop is a reminder on the initial project phase where only months since January 1986 were regarded. GPCC will ultimately fill this gap with future data acquisition. The data coverage for all months preceding June 1970 shows the typical behaviour of almost monotonically decreasing data availability due to loss or not yet performed data rescue with regard to digitization of historic data records. Only World Wars I and II shortly interrupt this monotonous decrease with age of the data records.

Despite the number of stations successfully recruited, the homogeneity of its global distribution is another quality criterion for a climate data set. Therefore, Fig. 5 demonstrates how the coverage of the GPCC database is composited (as of July 2012) with regard to the six regions defined by the WMO Regional Associations (RAs). Interestingly the total numbers are quite similar for the periods before World War II across all RAs except RA1 (Africa) and RA3 (South America), whereas a spread occurs for the periods post 1950, with RA4 (North America) and RA6 (Europe) showing the highest numbers up to 10603 and 11961 stations, respectively, followed by RA5 (Oceania including Australia) with up to 7706 stations, RA3 (South America) with up to 6657, and RA2 (Asia) with up to 5742 stations. For all months from 1901 until 1942, the GPCC database features the least number of stations for RA3, since 1950 RA1 (Africa) is the most weakly covered with only up to 5028 stations. Only in early 1971 there are slightly fewer stations for several months from RA2. Moreover, the most recent months being controlled by the availability of GTS connected stations have the lowest number of stations from RA3. Finally, Fig. 5 demonstrates that the time elapsing until the arrival of historic data is much shorter for RA4 and RA6, respectively, where it takes 5-7 yr in distinct contrast to RA1-3 where the increase through historic data is much smaller and it can take easily $20 \mathrm{yr}$ before data arrive at the GPCC. This situation challenges all efforts to achieve geo-temporal homogeneous station coverage, a prerequisite for highly reliable gridded trend analysis products solely based on in situ data. 


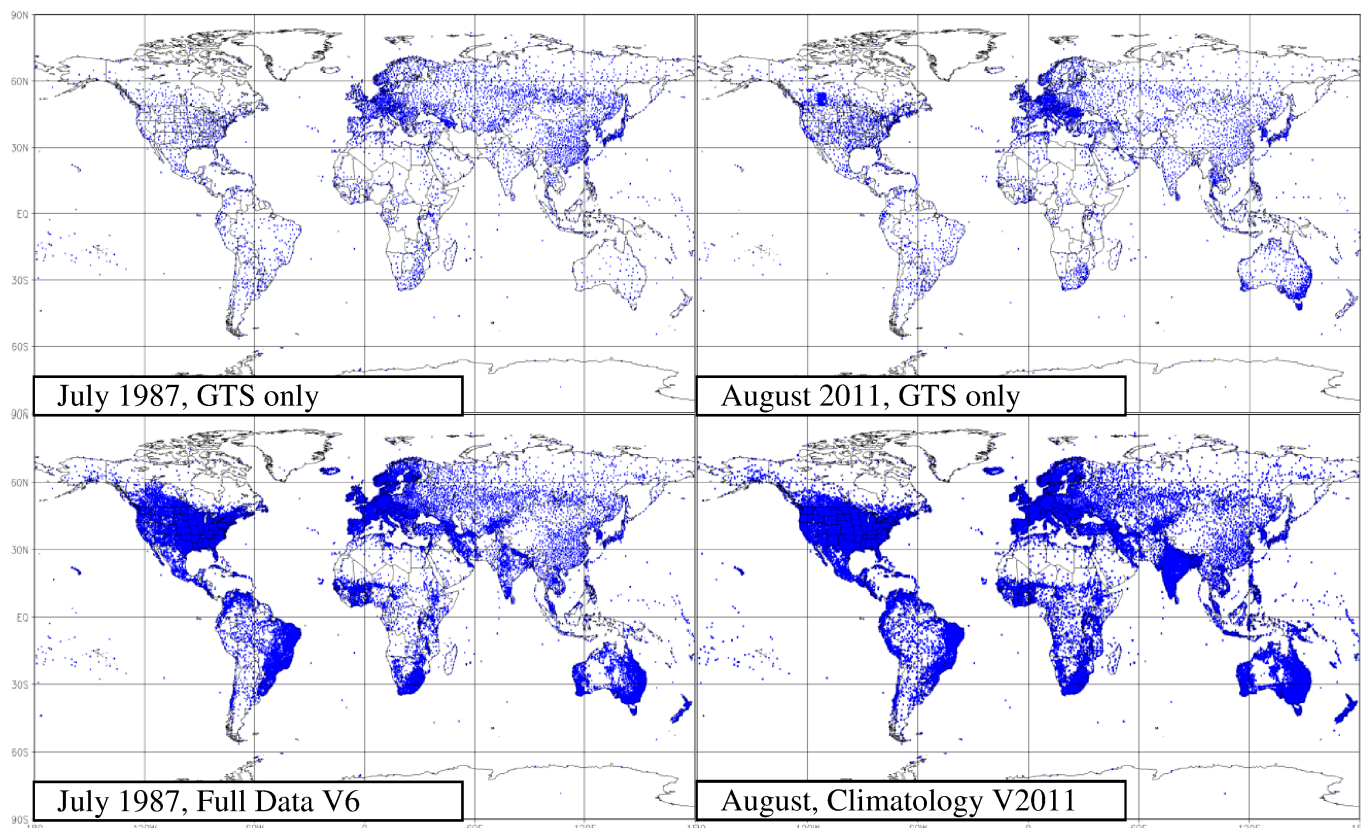

Figure 6. Left side: mapping of the 6325 stations reporting online via the GTS (top left) thus available for the GPCC Monitoring Product of July 1987 versus the 46711 stations available for GPCC Full Data Reanalysis of this well-covered month (bottom left). Right side: mapping of the 7964 stations reporting via the GTS for a recent monitoring product (August 2011) (top right) versus more than 67200 stations available for the background climatology (Version 2011) of this month (bottom right) featuring time series longer than $10 \mathrm{yr}$ at every station.

As listed in Appendix B, GPCC also holds records from the 19th century, but the overall coverage is currently too low to justify reanalysis of these early periods. Further successes in data acquisition and rescue might change this situation in the future.

Acquisition and integration of the additional non-GTS data from sources (i) to (v) takes much longer than through the GTS. Even delays of multiple years are accepted to ensure data are of high quality for reliable quantitative gridded reanalysis, which is crucial for global climate variability and hydrological studies. Therefore, the processing of the individual data collectives is a continuous GPCC activity and requires a number of steps:

1. identification of the file content (variables, period), general structure and specific format;

2. conversion of the file into a uniform GPCC format;

3. visualization of the reformatted file in maps and diagrams for a quick overall quality check;

4. clear identification of the stations and metadata control by a semi-automatic comparison of the delivered metadata and the existing GPCC stations master catalogue;

5. loading of the data into the RDBMS; and

6. semi-automatic quality-control of the monthly precipitation data based on a comparison of the data from the different sources with respect to the spatial and statistical data structure.

Availability of redundant data from different sources for the same stations and time at GPCC allows cross-comparison, quality-control and assessment of the accuracy of the data to be selected for analysis. This quality-controlled merging of data from all eight sources leads to the best possible and comprehensive database. The semi-automated QC system applied is detailed in Schneider et al. (2013).

All products are generated from this database by selecting data with respect to the data quality and product specifications. The spatial distribution of 6325 stations for the GTS data basis and of all 46711 stations available for a wellcovered month (July 1987) is shown in the left column of Fig. 6. For this month, the global 40000 -station criterion is met but not the homogeneity requirement, because the station density varies substantially with large data-sparse regions, in particular across parts of Africa, Central and South America, East and Central Asia. The spatial distribution of 7964 stations for the GTS database forming the August 2011 monitoring product versus the more than 67200 stations available for the GPCC Climatology for the month of August is shown on the right-hand side of Fig. 6. The row-by-row comparison in Fig. 6 demonstrates how the time constraint affects the data availability and station density; the column-by-column comparison in the top row reveals the limited temporal homogeneity of the GTS data coverage, and in the bottom row 
the improved data coverage for the longer integration period of a climatology versus a monthly reanalysis, which serves as an argument for the anomaly interpolation method introduced in Sect. 4.

The data coverage is very different depending on whether the data collection takes place with a time constraint (in online mode) or if time is a less important criterion. As will be shown in Sect. 7, both modes have their applications. In all cases, the availability of a reliable background climatology is crucial for the quality of the analysed product.

During the last two decades, the set of GPCC data and products has continuously grown both in temporal coverage, as well as in extent and quality of the underlying database. Until the end of 2003, the period covered by the GPCC reanalysis products reached back from present to just 1986, when the GPCP project was started. Later, in 2004 and 2008, GPCC extended this period back to 1951 and 1901 respectively, as shown in Fig. 1 where the evolution of the GPCC Monthly Precipitation Database throughout the dates of issue of the latest five versions of its Full Data Reanalysis product (GPCC-FD) is depicted. This product is only updated after a substantial growth of the database. It can be seen that the starting period of GPCC, 1986-1995, is still the period with the highest number of station data. However, a larger increase of the number of stations available for the period before 1986 and after 1995 is visible in particular for the updates from Version 3 to 5. The gap from 1986 to the years before is almost closed with the release of the most recent Version 6 issued in December 2011 and discussed in this paper. Moreover, the number of $30 \mathrm{k}, 35 \mathrm{k}$, and $40 \mathrm{k}$ stations is exceeded for the 56, 45 and $31 \mathrm{yr}$ periods from 1950-2005, 1959-2003 and 1962-1992, respectively, making those periods in particular reliable for analyses of means, anomalies, variability and even trends of global land-surface precipitation.

Figure 7 shows the evolution of the number of station months in the GPCC Monthly Precipitation Database (decades with data from 1901 onwards) during the period August until December 2011. It indicates that the extension of the GPCC database concerning historical data (data before year 1951) started in 2007. The historical extension of the GPCC database during the last $8 \mathrm{yr}$ is very visible by looking at the decades with data before 1981. Altogether the number of station months tripled from 13 to 40 million making GPCC the host of the world's largest and most comprehensive collection of monthly precipitation data, which is continuously extended.

Figure $8 \mathrm{a}-\mathrm{h}$ show the temporal evolution of the spatial coverage of the GPCC database (indicated by the number of stations available for analyses in each $2.5^{\circ} \times 2.5^{\circ}$ grid) used for GPCC Full Data Reanalysis Version 6 issued in December 2011. Green, blue and magenta colours indicate grids with a nominal sampling error of less than $10 \%$ of the precipitation total on the grid according to Jenne and Joseph (1985). This criterion is unfulfilled across vast areas, in particular during the first two decades (Fig. 8a, b), but later the data coverage of the GPCC is good enough for a fair spatial homogeneity of the station density. Figure $8 \mathrm{~h}$ shows the consequences of the rather limited number of available GTS stations, leading to a wide-spread exceedance of the $10 \%$ sampling error criterion. Comparison of Fig. 8h representing the GTS station coverage with the other Fig. 8a-g shows the added value of GPCC's successes in historic data acquisition.

Finally Fig. 9 and Appendix B give a country-specific account on GPCC's efforts towards universalization of the data contributions and coverage. Clearly data acquisition remains an ongoing challenge for the GPCC. It is backed by WMO through support letters of the WMO Secretary-General and by endorsements made by the WMO GCOS Atmospheric Observation Panel for Climate (GCOS, 2011).

\section{Data processing and quality control}

The collected data are imported into a relational database, where they are kept in eight separate source-specific slots. This methodology allows for a source-specific crosscomparison of the data. As no source is error-free, each is allowed to provide for the reference information on a case-bycase basis. This is achieved by a comparative analysis of data entries from different sources relevant for the same or neighbouring stations. Typical errors identified during data import are factor-10 (caused by a format shift or coding errors), factor 2.54 or also factor 25.4 errors due to wrong inch to $\mathrm{mm}$ conversions, shifts of the reference time, or geo-reference errors that had already affected the data before arrival at the GPCC. Any time new data are imported to the database, an elaborated procedure is applied to compare the accompanying metadata of the pertinent stations to the metadata already available for this station from the database. In case of discrepancies (e.g. deviating coordinates), external geographical sources of information are utilized to decide whether a correction of the metadata information in the database is required or not. Moreover, the precipitation data to be imported are compared against a background statistic. Exceptional values are checked and either confirmed, corrected if possible, or flagged as erroneous and thereby excluded from the analyses. This approach requires a high level of human interaction, due to the complexity of the error analysis, which varies strongly from case to case in the absence of general valid screening criteria. Nevertheless, despite all corrections applied by the GPCC, a set of the original data is also kept, allowing backtracking of all corrections. A detailed account on GPCC's data processing and quality control is presented by Schneider et al. (2013).

\section{Calculation of gridded precipitation data sets (interpolation method)}

The calculation of area means on the grid cells from gauge observations consists of three major steps: (i) the interpolation from stations to regular latitude/longitude grid points 


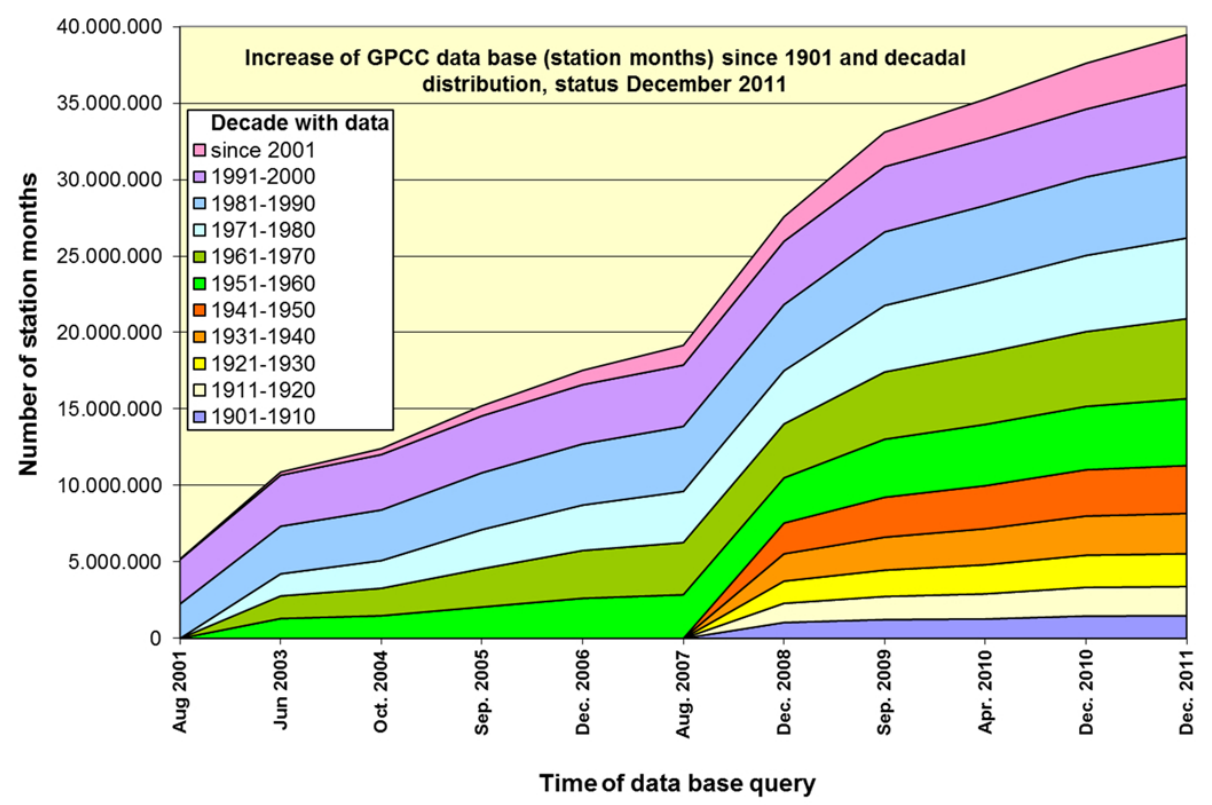

Figure 7. Evolution of the GPCC Monthly Precipitation Database between August 2001 and December 2011 shown by the number of station months already accumulated at the date (time) of the database query. The decades covered are additionally colour-coded.

staggered at $0.25^{\circ}$ resolution, (ii) the calculation of areamean precipitation for grid cells sized $0.25^{\circ}$ (GPCC-CLIM) or $0.5^{\circ}$ (GPCC-FD, -MP), and (iii) the assessment of areamean precipitation for larger grid cells $\left(0.5^{\circ}, 1^{\circ}\right.$ or $\left.2.5^{\circ}\right)$ or other areas (e.g. river basins).

\subsection{Interpolation of gauge data onto regular grid points}

For the GPCC (background) Climatology and the Full Data Reanalysis products on a $0.25^{\circ}$ latitude/longitude base grid, GPCC still prefers the very robust empirical interpolation method SPHEREMAP. The method constitutes a spherical adaptation (Willmott et al., 1985) of Shepard's empirical (angular distance) weighting scheme (Shepard, 1968), which takes into account the following:

1. the distances of the stations to the grid point (for limited number of nearest stations),

2. the directional distribution of stations in relation to the grid point (in order to avoid an overweighting of clustered stations), and

3. the gradients of the data field in the grid point environment.

This choice was made in 1991 following external studies (Legates, 1987; Bussieres and Hogg, 1989) and internal inter-comparison studies (Rudolf et al., 1992, 1994) indicating the SPHEREMAP method of being particularly suitable for the analysis of a global precipitation climatology. In an inter-comparison study of four different interpolation schemes (Bussieres and Hogg, 1989), it was the best of the empirical schemes and performed almost as well as optimum interpolation. Hofstra et al. (2008) confirm this finding for the precipitation parameter when comparing two angular distance weighting methods against four other interpolation methods including global and local kriging. For SPHEREMAP, Willmot et al. (1985) apply an angular distance weighting method for all stations beyond a minimum distance to the grid point. However, if stations closer are found, their method only relies on those stations and applies a simple arithmetic mean for them, while neglecting all stations outside this environment. This leads to the neglect of many potentially useful stations and information in areas of high station density. Therefore in 1994, GPCC introduced the following modifications to interpolate data of stations surrounding each point of the stereographic GPCC product grids:

- Vicinities are defined by concentric circles of different radii (see Fig. 10) defining threshold distances to the grid point regarded.

- A second distance $\left(\varepsilon_{2}\right.$, circles filled green in Fig. 10) is introduced and defined by $50 \%$ of the grid cell size (depicted by grid lines in Fig. 10). This approach still leaves up to $21.5 \%$ stations unprocessed, but any larger circle would lead to a double use of stations, as the green circles in Fig. 10 would start to overlap each other.

- $\varepsilon_{1}$ is defined by $10 \%$ of the grid size instead of Eq. 14 in Willmot et al. (1985). 


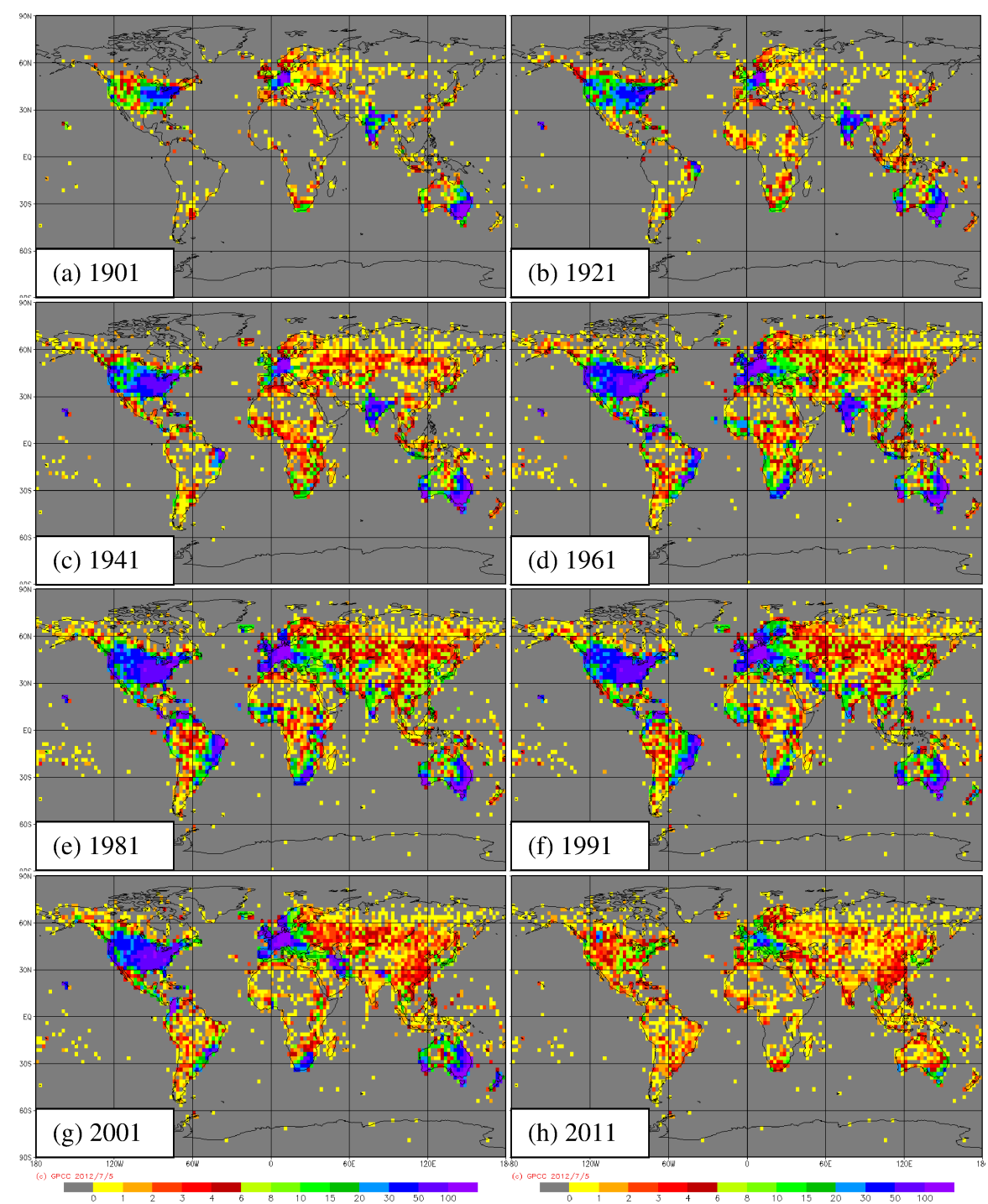

Figure 8. Spatial distribution of the number of stations per $2.5^{\circ} \times 2.5^{\circ}$ grid available for the July reanalyses (Version 6) of (a) year 1901 with 10907 stations, (b) year 1921 with 16688, (c) year 1941 with 24602 , (d) year 1961 with 41 032, (e) year 1981 with 42670 , (f) year 1991 with 42 511, (g) year 2001 with 36156, and (h) year 2011 with 9726 stations.

- The simple arithmetic mean method is now only applied if stations are found within the vicinity defined by radius $\varepsilon_{1}$ but not within the wider (green) circle of $\varepsilon_{2}$.

- In all other cases, stations are interpolated with the original weighting method, even those located closer than $\varepsilon_{1}$.

- For the normalization step of the weighting method, we keep Shepard's method for the calculation of the combined weighting (term w in Eq. 7 of Wilmot et al., 1985, and $t$ in the first equation of page 520 in Shepard, 1968, respectively).
- The determination of the radius to the grid point beyond which the weighting of a station reaches zero is used as published by Shepard (1968).

In view of the potentially high number of stations involved in the interpolation process $(>10000)$, it is feasible to introduce an intelligent search algorithm to identify the closest stations to be utilized for the interpolation of each grid cell. Instead of ranking the distances across all stations, we apply a clustering of stations on $2^{\circ} \times 2^{\circ}$ sized grid cells in advance and limit the search algorithm to a search window 1.75 times as long as the cluster size (here $3.5^{\circ}$ ) at the Equator. Towards higher latitudes, the size of the search window is conserved in the canonical manner by scaling with the cosine of the latitude. The $175 \%$ oversizing of the search window warrants that it 


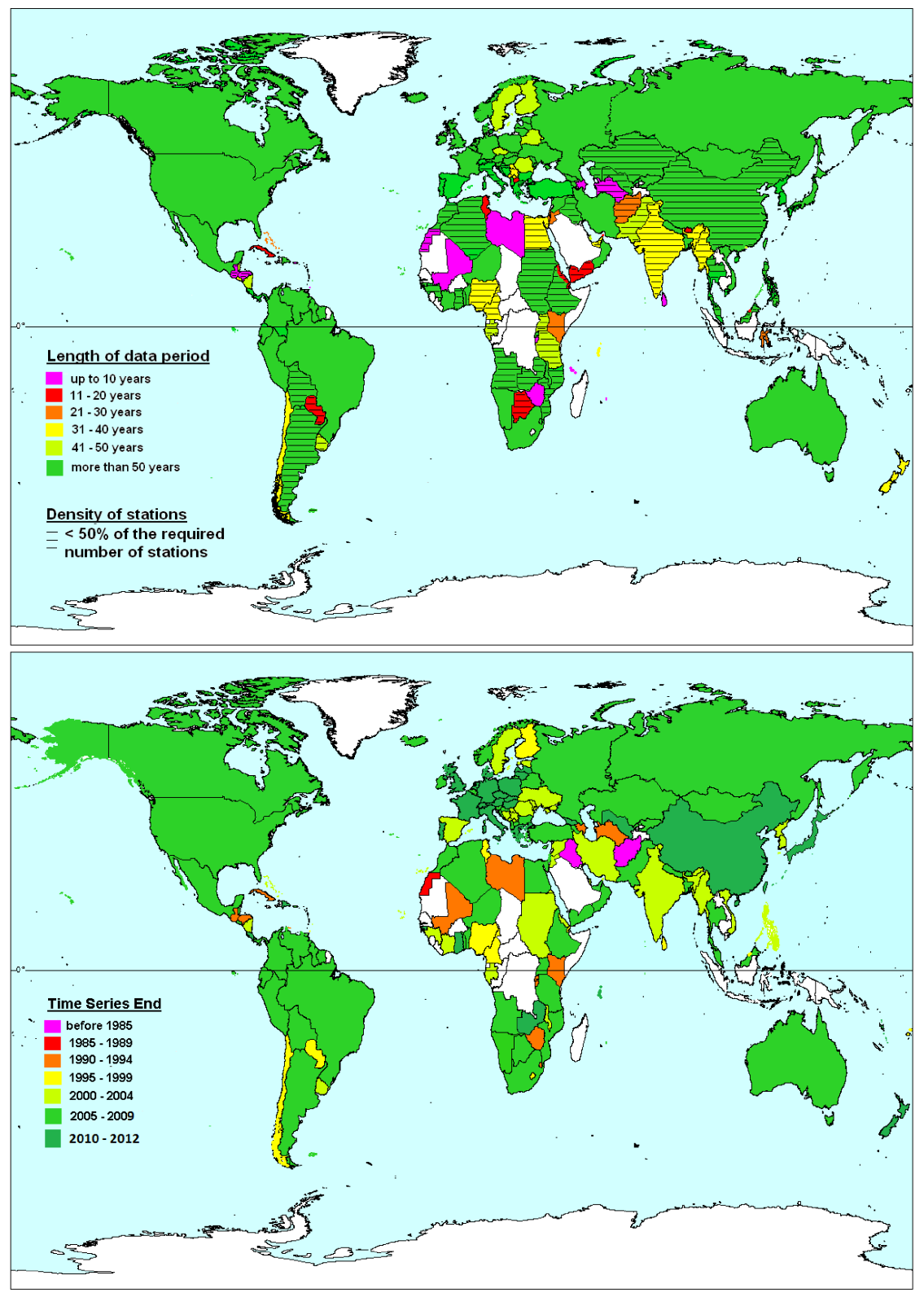

Figure 9. Contributions of historic precipitation data sets by WMO member countries to GPCC in terms of length of data period covered (top) and most recent historical data involved (bottom).

does not miss stations just outside the closest cluster. The target number of stations to be ranked is 16 . If the original search window finds fewer stations than this target number, the window is doubled in size and the search is repeated until the target number is reached. For latitudes higher than 87.5 degrees, the whole area is regarded as one cluster giving one for each pole region.

\subsection{Calculation of gridded precipitation for the base grid and coarser grids}

For the products based on GPCC's full database, the first area-average precipitation is calculated as an arithmetic mean from the interpolated data from (up to) four grid points representing the corners of a $0.25^{\circ} \times 0.25^{\circ}$ grid cell. In doing so, only those corners located across land are used, so that the mean represents the land-surface precipitation. The $0.25^{\circ}$ grid cell means only represent the land-surface proportion of the total grid cell area as derived from GTOPO-30 (USGS, 2013) data projected on the same evaluation grid. Further user advice is provided in Sect. 8.2 for the calculation of mean land-surface precipitation (and their time series) based on GPCC data products. For the real-time products, the based grid has a 0.5 degree resolution instead of $0.25^{\circ}$, reflecting the weaker data coverage. 


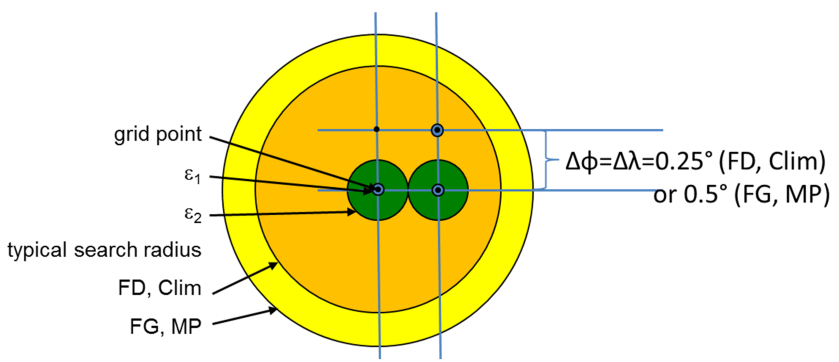

Figure 10. Schematic view on distance circles around each point of the GPCC analysis grid being relevant to describe the GPCC modification of the SPHEREMAP interpolation of station data.

To allow utilization of the precipitation totals for multiple purposes, area-average precipitation is calculated by the GPCC onto coarser grids $\left(1.0^{\circ}\right.$ or $\left.2.5^{\circ}\right)$ from the $0.5^{\circ}$ base grid means and also published. In doing so it is important to take into account the high-latitude convergence of the meridians and the relative land-surface proportion of the grid cells used. The following formula applies:

$\mathrm{PAM}=\frac{\sum<\mathrm{SP}_{i j}>\cdot \cos \left(\varphi_{j}\right) \cdot \mathrm{LP}_{i j}}{\sum \cos \left(\varphi_{j}\right) \cdot \mathrm{LP}_{i j}}$

with $\mathrm{PAM}=$ precipitation area mean, $\langle\mathrm{SP}\rangle=$ mean scaled (gridded) precipitation, $\mathrm{LP}=$ relative land-surface proportion, $\varphi=$ latitude, and $i, j=$ horizontal indices counting positive eastward and northward, respectively.

\section{Uncertainty information}

\subsection{The three basic error types}

The uncertainties associated with the GPCC gridded products are attributable to three typical sources of errors:

i. Systematic errors yield biases of gauge measurements, such as wind-induced gauge under-catch (when droplets and particularly snowflakes are drifted by the wind across the gauge funnel), wetting and evaporation losses, and underestimation of trace precipitation amounts (Ye et al., 2004; Goodison et al., 1998).

ii. Stochastic sampling errors occur due to a sparse network density and/or uneven distribution of measurement sites (spatially heterogeneous data density). It mainly depends on the density of the gauge locations (see Sect. 5.2) and the variability of the precipitation field according to the climatic/orographic conditions (WMO, 1985; Rudolf and Schneider, 2005; Rudolf et al., 1994).

iii. Residual errors occur, e.g. resulting from spatial and temporal discontinuities of precipitation measurements associated with changes of observational methods and differences of observational techniques used in different countries (homogeneity).

To address these problems the GPCC provides a gridded quantification for the following errors:

i. The systematic gauge-measuring error occurs as (a) climatic- or (b) SYNOP-derived under-catch factors:

a. Error correction on climatic time scale: parameters affecting the efficiency of measurement are features of the instrument used (size, shape, exposition etc.) and the meteorological conditions (wind, precipitation type, air temperature, humidity, radiation) during the precipitation event. This information is not available for most of the precipitation stations. The global distribution of the error has been estimated for long-term mean precipitation (Legates and Willmott, 1990) and is provided as a climatic mean correction factor for each calendar month. The error and thus the required correction is large in snow regions in cold seasons.

b. SYNOP-derived correction: with the GPCC-MP available for all months since January 2007, a new on-event correction method for systematic gauge measuring errors is also available at GPCC (Fuchs et al., 2001). This event-based correction is usually smaller than the climatological correction; however it is still a rough bias estimate based only on wind, weather, temperature and humidity data retrieved from synoptic observations of ca. 6000 stations available worldwide. These corrections have been calculated for the GTS-based Monitoring Product publicly available for all months since January 2007.

ii. The sampling error of gridded monthly precipitation data has been quantified by GPCC for various regions of the world. Based on statistical experiments using data from very dense networks, the relative sampling error of gridded monthly precipitation is between \pm 7 to $40 \%$ of the true area-mean, if 5 rain gauges are used, and with 10 stations the error can be expected within the range of $\pm 5 \%$ and $20 \%$ (Rudolf et al., 1994). The error range for a given number of stations represents the spatial variability of precipitation in the considered region. In Sect. 5.2 we provide a systematic assessment of the sampling error.

iii. The residual errors mainly related to the data homogeneity issue are addressed by construction of a special Homogenized Precipitation Analysis (HOMPRA) data set that relies on a carefully chosen sub-set of stations featuring time series of particular length, completeness and temporal homogeneity. The method has been introduced by Beck et al. (2005) for the construction of the 


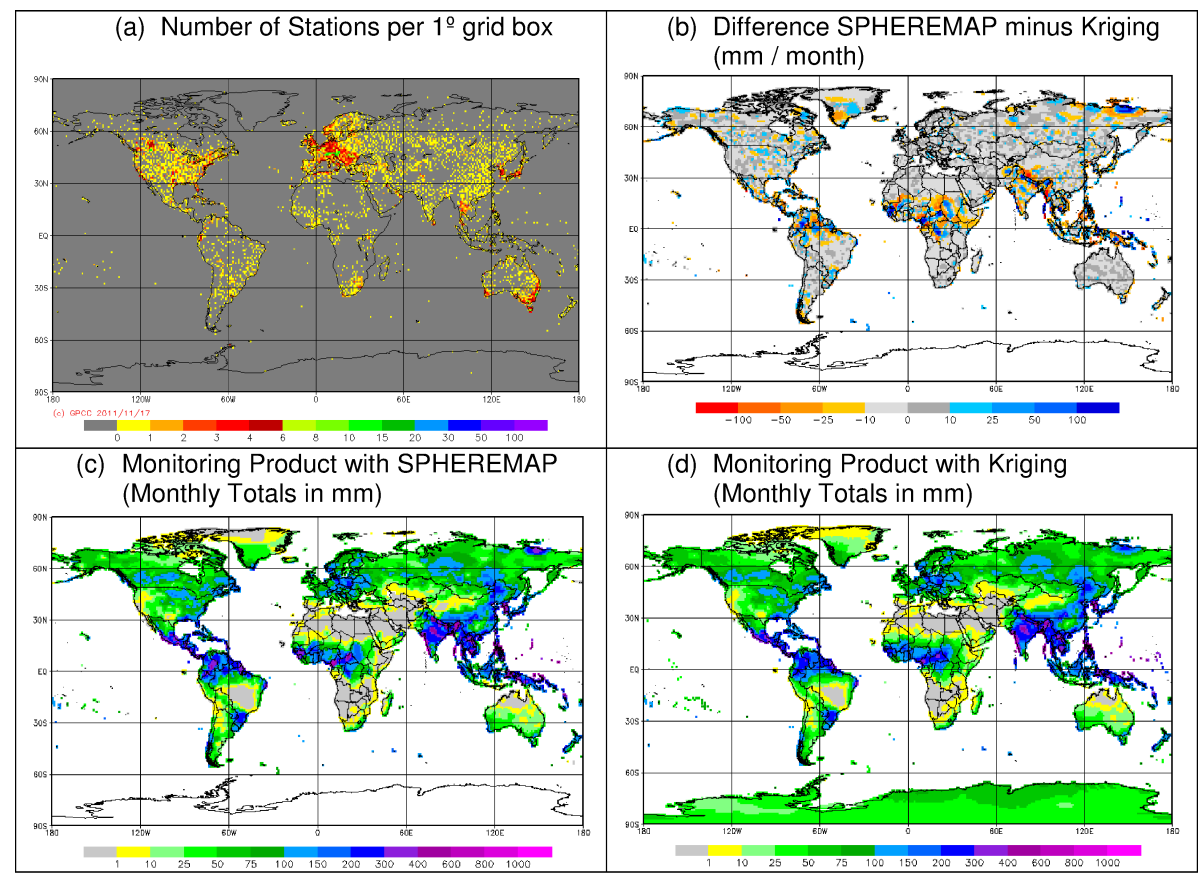

Figure 11. Comparison of the two GPCC interpolation methods for the GPCC July 2011 monitoring product: (a) stations available via GTS for the real-time analysis, (b) difference of SPHEREMAP and kriging-based interpolation, (c) SPHEREMAP results, and (d) kriging-based result.

VASClimO data set (based on a sub-set of some 9300 stations) to be replaced soon by HOMPRA that will build on more than 16350 stations. For the Full Data Reanalysis the homogeneity is less controlled, although a check on the stations collective was also performed (H. Österle, personal communication, 2008, 2010) to remove stations with obvious jumps in their precipitation records.

\subsection{A systematic assessment of the sampling error}

Two assessments of the GPCC products' sampling error are presented here: (i) a qualitative assessment through comparison of the same products interpolated with an alternate interpolation method to SPHEREMAP, i.e. ordinary kriging (Krige, 1951) according to the adaption of Rubel and Hantel (2001), and (ii) a quantitative assessment through calculation of the mean absolute error (MAE) with the jackknife error (Miller, 1974) for those two interpolation methods and the rather simple arithmetic mean method.

For the qualitative assessment, Fig. 11 shows the difference of GPCC's SPHEREMAP and kriging for the particularly challenging real-time monitoring product analysis at $1^{\circ}$ spatial resolution. It should be noted that for this comparison the absolute values, but not the anomalies, have been interpolated. Besides the difference field plotted in the upper right part and the monitoring product from both interpolations (lower row), the number of stations included in the analysis is also shown in the upper left graph. The example demonstrates that deviations occur only in data-scarce areas where the minimum constraint of 4 stations per grid cell is not fulfilled. However, the deviations are only substantial in regions where station scarcity and high precipitation variability coexist, i.e. the equatorial regions of South America and Central Africa plus the southern rim of the Himalayas. Moreover, singular stations with no neighbouring stations across long distances naturally produce differences (e.g. Greenland or patches across northern Siberia). In these areas the kriging method features somewhat smoother patterns and is thus a considerable alternative to SPHEREMAP.

On the other hand, many station-scarce areas exhibit very little deviations, which gives confidence in the quality of the SPHEREMAP interpolation applied in particular for the nonreal-time GPCC Full Data Reanalysis and the GPCC Climatology which can utilize a data coverage that is overall five and eight times better, respectively (Fig. 12). A comparison of Fig. 12b with Fig. $11 \mathrm{~b}$ demonstrates the diminishing effect of the interpolation method with increasing data density and sampling.

For the quantitative assessment of the sampling error of the GPCC products in dependence of station density and gridding (interpolation) method, we use the MAE to calculate the sampling error of arbitrarily resampled data sets according to the jackknife error approach (Miller, 1974). In doing so the following steps have been taken:

a. reducing the data density across Germany by dropping randomly almost all of the 4000 stations available 


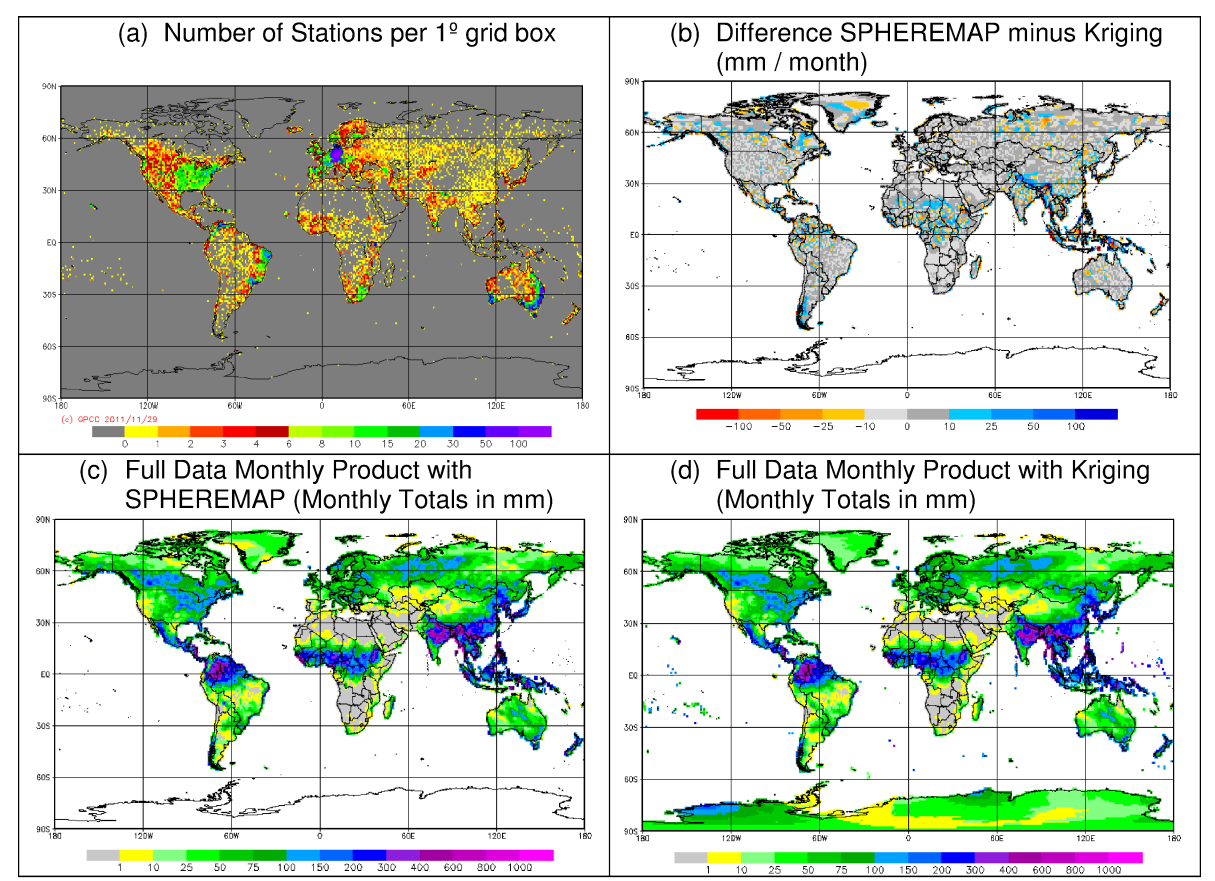

Figure 12. As Fig. 11 but utilized for the GPCC July 1986 Full Data Reanalysis product.

(for this particular study only), to keep just 219 of them, yielding a horizontal homogenized station density across Europe;

b. defining 150 collectives of 300 stations each to distribute the 45000 stations utilized into;

c. randomly picking up 16 collectives to form the reference data set (of 4800 stations);

d. utilizing remaining stations to interpolate to the locations of the reference stations;

e. calculating the absolute deviations (jackknife errors) at the reference station locations;

f. repeating (c)-(e) 50 times with a different choice of reference stations according to $(\mathrm{c})$;

g. calculating MAE from the 50 jackknife errors yielded;

h. the steps (c)- $(\mathrm{g})$ are then repeated assuming station networks of increasing number starting from 900, and increasing in steps of 1500 up to 38700 stations;

i. the steps (c)-(h) are repeated for the three interpolation methods "arithmetic mean", "modified SPHEREMAP" and ordinary "kriging" utilized at GPCC;

j. the steps (a)-(i) are performed on the "absolute" precipitation totals and on the "anomalies", utilizing the Climatology Version 2011 (GPCC-CLIM) as a background field.
The results, compiled in Fig. 13, can be summarized as follows:

- The MAE is much more sensitive to the decision of whether the anomalies or the absolute values are interpolated in comparison with the choice of the interpolation method (arithmetic mean, modified SPHEREMAP or kriging).

- The sampling error can still exceed $25 \mathrm{~mm}$ per month for gauge networks of low density.

- If a sufficient number of stations is available for the interpolation, the choice of the interpolation methods has only a marginal impact.

Conducting the same assessment again with the mean square error and the root mean square error yields qualitatively similar results and is therefore not further discussed here.

\section{Construction of the 50 -yr background climatology (GPCC-CLIM)}

Since the introduction of the anomaly-based interpolation method in 2008, the monthly GPCC Climatology product serves as a background field for the analysis, and is thus of central importance for all products.

Anytime the GPCC database has grown substantially due to successful acquisition and pre-processing of further historic data, including the quality assurance and control performed on the data as described in Sect. 3 and by Schneider et al. (2013), a new climatology product is built as follows: 


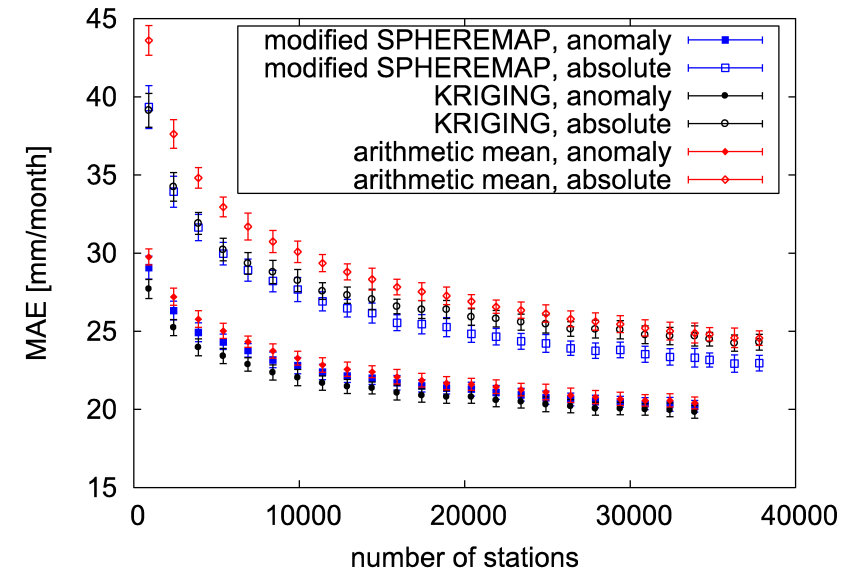

Figure 13. Mean absolute error (MAE in $\mathrm{mm} / \mathrm{month}$ ) of 50 jackknife errors calculated from an according number of re-samplings. The calculation has been repeated in dependence of the number of stations available to the network (staggered by steps of 1500 stations) and the interpolation method (six choices) utilized.

- Selection of monthly precipitation data from the GPCC database for the period 1811-2010 comprises all stations with a of minimum $10 \mathrm{yr}$ (120 months) data availability out of the total record length of the up to $200 \mathrm{yr}$ from 1811-2010. More than 67200 stations were selected by this screening for the most recent Climatology (Version 2011; Meyer-Christoffer et al., 2011a-d), released in December 2011.

- For each of these stations, a time series is constructed from up to eight source-specific time series available.

- Depending on the lengths of the time series yielded, climatic normals are constructed for the reference periods 1951-2000, 1931-1960, 1951-1980, 1961-1990 and 1971-2000. It should be noted, however, that we still accept missing data of up to $10 \mathrm{yr}$ in total for each month.

- If none of these periods is covered by the series examined, a climatic normal is still calculated for arbitrary periods and still divided into a long and an arbitrary category.

- Subsequently, the 12 monthly minima and maxima of each station's time series for the period 1901-2010 are calculated to be available for interactive sanity checks.

- These 24 station-specific (located) extreme values are then transcoded into KML files to perform a visual interactive check of the stations' time series while making use of the "Google Earth" software application.

- In doing so, necessary corrections (e.g. relocation of a station) are fed back into the database and the associ- ated stations are reprocessed again (which means reexamination from the first bullet of this list).

- Based on the corrected data, station-specific climatic normals are calculated for the reference periods possible (preferably 1951-2000).

- Subsequently, these normals are loaded to the RDBMS to make them available for gridding with SPHEREMAP yielding the climatology product at $0.25^{\circ}$ spatial resolution.

- Finally, reduction of the high-resolution gridded product to $0.5^{\circ}, 1.0^{\circ}$ and $2.5^{\circ}$ grids is performed with the methods described in Sect. 4.

\section{The GPCC products and their major sample applications and capabilities}

Plenty of applications of the GPCC data products have been documented and published (Oldenborgh et al., 2012; Parker et al., 2012, Hennon et al., 2011; Rubel and Kottek, 2010; Yatagai et al., 2009, 2012; Dinku et al., 2008; Gruber and Levizzani, 2008; Kaspar and Cubasch, 2008; Wild et al., 2008; Kottek and Rubel, 2007; Rajeevan et al., 2005; Rudolf and Rubel, 2005). In order to address the wide spectrum of potential users, the GPCC has designed four different gridded monthly precipitation products, each one tailored for a characteristic use case while being optimized for a corresponding particular requirement as follows:

- Best timeliness to support watch functions and drought monitoring;

- Best quality at regular and high availability to serve as reference in situ data sets for regularly issued satellitebased products;

- Best accuracy for verification of model-based case studies, re-analyses and for global assessment of water resources; and

- Best homogeneity for global analysis of precipitation variability and trends.

\subsection{The GPCC First Guess Product (GPCC-FG, for best timeliness)}

This global gridded product of the monthly precipitation, provided on one lat/long grid of $1.0^{\circ}$ resolution (Ziese et al., 2011), is based on interpolated precipitation anomalies from more than 6000 stations worldwide. Data sources are synoptic weather observation reports (SYNOP) received at DWD via the WMO GTS, and climatic mean monthly precipitation totals extracted from GPCC's global normals collection (mainly 1951-2000, or other reference periods as described before). An automatic-only QC is applied to these data. Since 


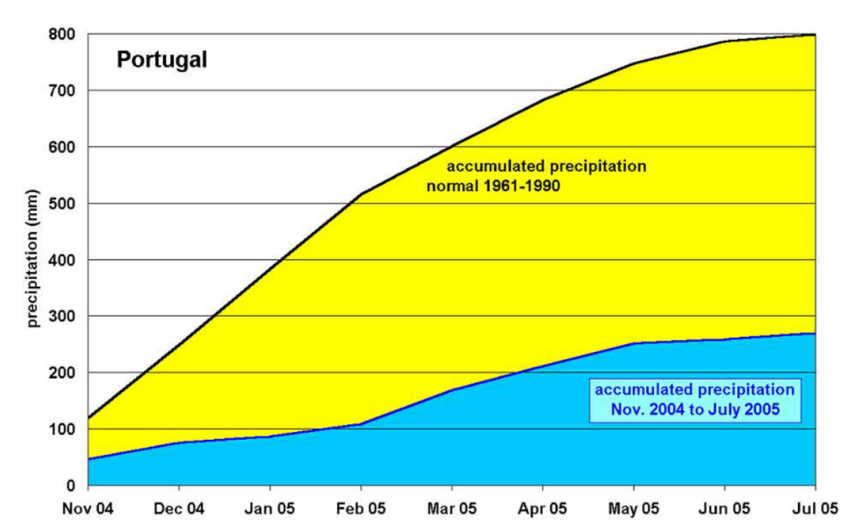

Figure 14. Accumulated precipitation totals (based on GPCC First Guess) and accumulated GPCC precipitation normals 1961-1990 indicating an increasing precipitation deficiency in year 2005 in Portugal.

August 2004, GPCC First Guess monthly precipitation analyses are available within 3 to 5 days after end of an observation month.

A major sample application lies in the field of drought watch and water stress monitoring where the FG product serves the input for near real-time drought monitoring applications, as has been demonstrated by the Food and Agriculture Organization FAO (2011) and is still active at the Hazard Research Centre of the University College of London (UCL, 2011). Figure 14 illustrates a typical drought monitoring application of the First Guess Product in accumulating monthly totals for a certain period prior to the assessed date for a region chosen to be Portugal here.

\subsection{The GPCC Monitoring Product (GPCC-MP, for best quality at regular availability)}

This global gridded product of monthly precipitation (Schneider et al., 20011a, b) is based on SYNOP and monthly CLIMAT reports received near real-time via GTS from ca. 7000-8000 stations (after high level QC) and is available within two months after the observation month on two lat/long grids of $2.5^{\circ}$ and $1.0^{\circ}$ resolution. This is the oldest GPCC product that went operational in 1986 and has continuously been updated every month since then. The analyses are based on automatic and intensive manual quality control of the input data. In general, the GPCC-MP is known as the best regularly issued in situ and GTS-based monthly landsurface precipitation reference product publicly available.

A primary sample application is the calibration of satellitebased data products: the GPCC Monitoring Product serves the in situ component to the satellite-gauge combined precipitation analyses of GPCP (Huffman et al., 1995; Adler et al., 2003) and of CMAP (Xie and Arkin, 1997). Figure 15 shows an example visualization of the GPCP satellite-gauge product in terms of the anomaly against a GPCP 1961-1990

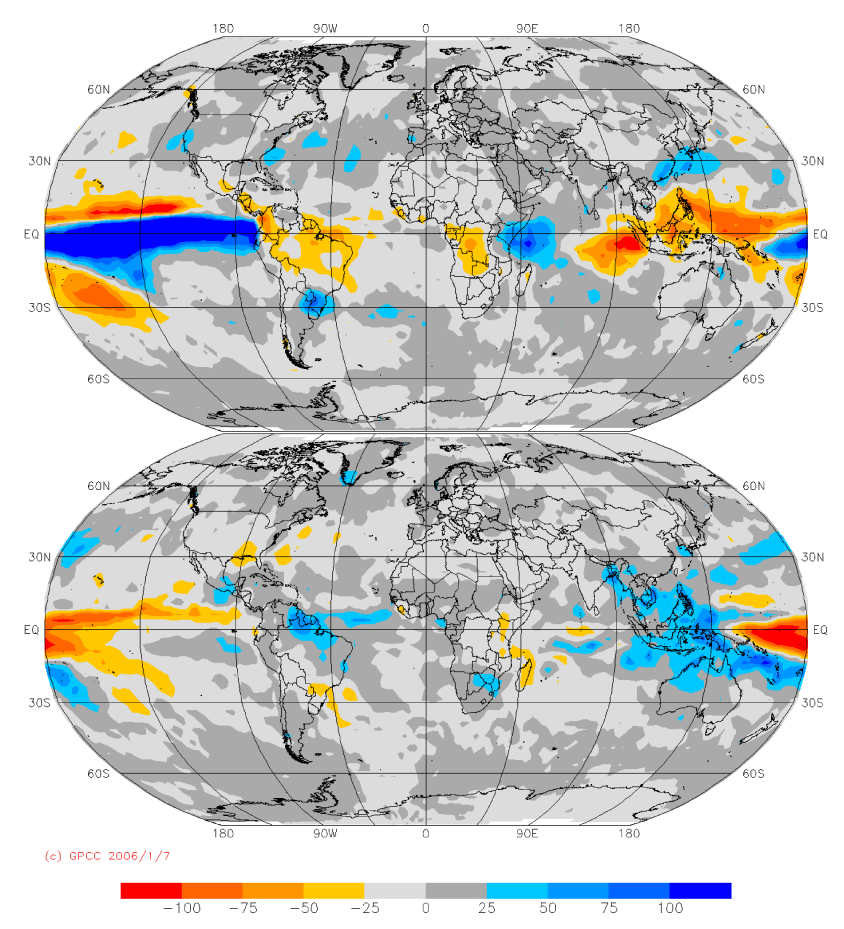

Figure 15. Example visualizations of the annually averaged precipitation anomaly (absolute deviations in $\mathrm{mm} / \mathrm{month}$ ) based on the GPCP Version 2 product that is calibrated against the GPCC Monitoring Product reference across land surfaces. The plots show the typical inversion of the anomaly patterns controlled by the El NiñoSouthern Oscillation (ENSO) for the southern hemispheric years ending in June 1998 (top, El Niño) and June 2000 (bottom, La Niña).

climatology for the El Niño (top plot) and La Niña (bottom plot) controlled southern hemispheric years ending in June 1998 and 2000, respectively. Across the land surfaces, each product relied on the 12 GPCC monthly monitoring products. The GPCC-MP product is also utilized for the annual WMO statement on the status of the global climate (WMO, 2011b) and the Annual State of Climate of the Bulletin of the American Meteorological Society (Parker et al., 2012; Hennon et al., 2011). Early assessments on larger-scale extreme events, like the Pakistan flooding in 2010 and the Thailand flooding in 2011 (Oldenborgh et al., 2012), also rely on this high availability and quality product.

\subsection{The GPCC Full Data Reanalysis (GPCC-FD, for best accuracy)}

This global gridded product of monthly precipitation (Schneider et al., 2011c-e) is based on near real-time and non-real-time data. These are data from NMHS, regional and global data collections, CLIMAT bulletins and values calculated from SYNOP reports. It uses the same stations applied to calculate the GPCC Climatology product, i.e. more than 67200 stations for Version 6 . Grid resolutions are $0.5^{\circ}, 1.0^{\circ}$ 

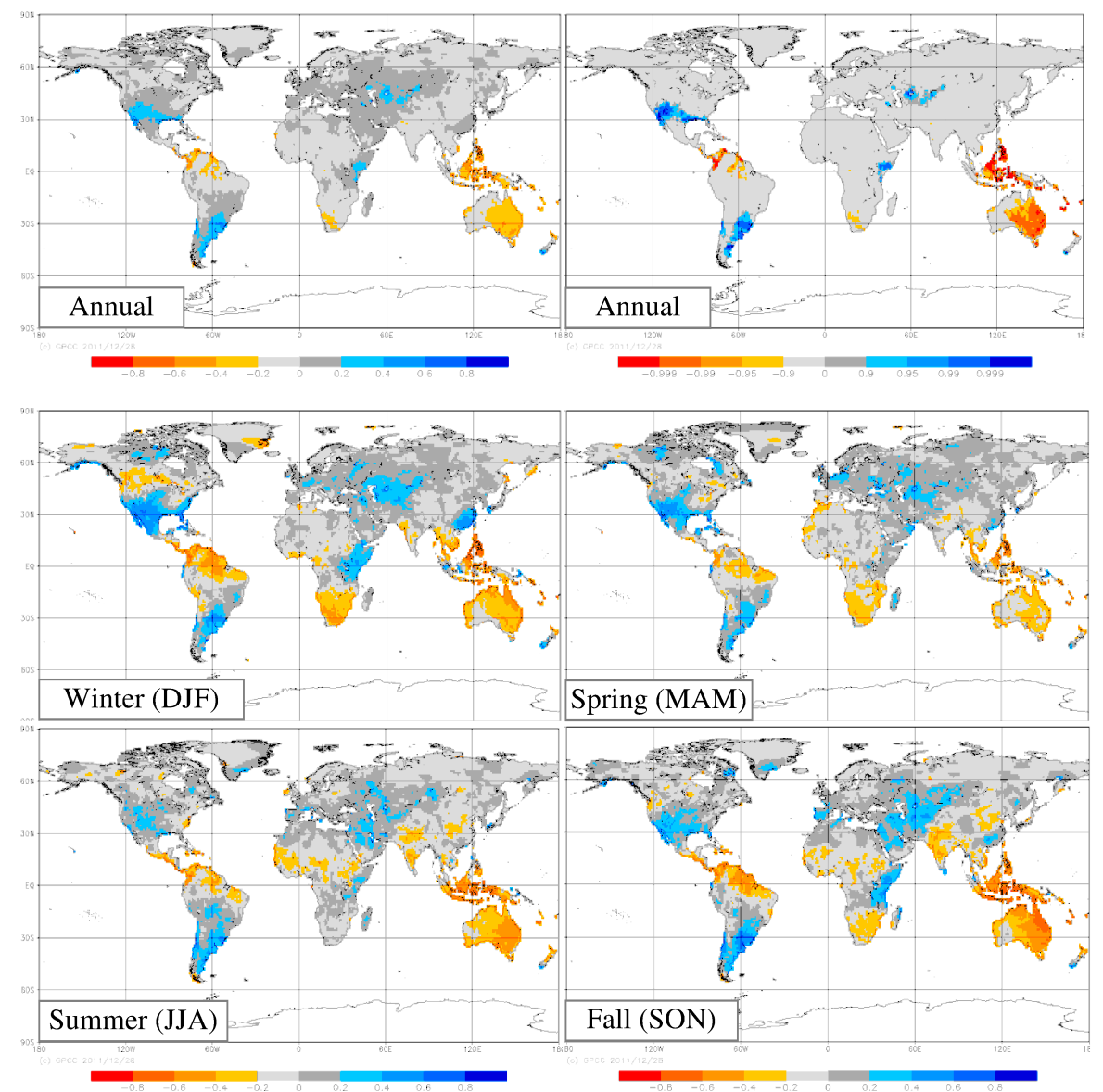

Figure 16. Upper panel, left: correlation of the negative, annually averaged southern oscillation index (SOI) against the precipitation time series at every $0.5^{\circ}$ sized grid cell for the period 1901-2010. Top right: significance of this annual correlation. Bottom panels: as upper panel left but for the seasons winter (DJF, upper left), spring (MAM, upper right), summer (JJA, lower left) and autumn (SON, lower right).

and $2.5^{\circ}$. The QC is extended by an additional manual control. Upon substantial improvements of the database, a new version of this product is released, which happens approximately every $1-3 \mathrm{yr}$.

Major sample application of the GPCC-FD product is the verification of reanalysis products like the ERA-Interim reanalysis (Dee et al., 2011). They become more and more popular to hindcast the most recent decades of the global climate and to serve geo-temporal homogeneous and contingent reference data sets for the validation of climate prediction models. However, the quality of the precipitation data in these model reanalyses requires particular attention as precipitation is not a diagnostic but a prognostic parameter in the underlying global numerical weather prediction models utilized. Hence there is a need for purely observational analysis products of precipitation. It is the GPCC-FD that proves to have a particular strength here (Simmons et al., 2010; Simmons, 2011). Its 110-yr coverage will also allow provision of reference information for the currently running ERA-CLIM effort (http://www.era-clim.eu/) to reanalyse the entire 20th century.
The GPCC-FD is also well suited for analysis of historic global precipitation and the global water cycle by providing reference information on the precipitation for certain periods and regions of interests due to its optimization for station density yielding a minimized sampling error of the interpolation. This makes it also most suitable to study the global water cycle, arctic precipitation (Mächel et al., 2012) and to derive mean precipitation across regional and global river catchments.

Moreover, we demonstrate that the diagnosis of regions sensitive to indices of natural large-scale variability of pressure patterns, known to govern precipitation patterns like the North Atlantic Oscillation (NAO) and the El Niño-Southern Oscillation (ENSO) index (SOI), is facilitated by the GPCCFD product. In doing so, we have correlated the monthly resolved temporal evolution of precipitation for every $0.5^{\circ}$ sized grid cell of the GPCC-FD product against the negative SOI (Fig. 16) and NAO (Fig. 17). The sensitive regions, identified by areas of positive or negative correlation of the annual totals (left plots in top panels of Figs. 16 and 17), are congruent with the areas of significant correlation 

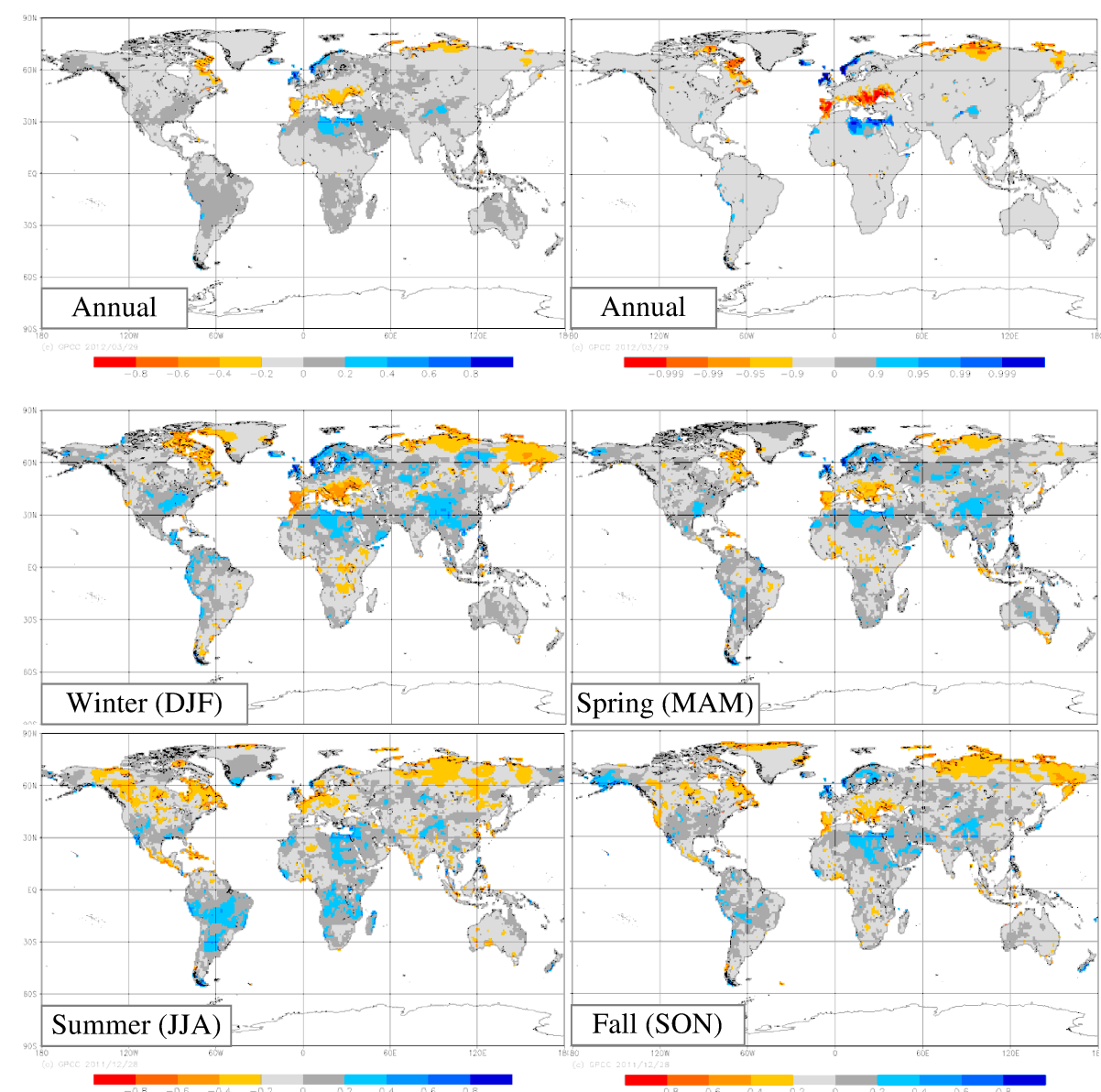

Figure 17. As Fig. 16 but for the North Atlantic Oscillation Index.

(right plots of top panels of Figs. 16 and 17). For the negative SOI (positively correlating with the typical sea surface temperature (SST) indices, e.g. the Niño 3.4 region $5^{\circ} \mathrm{N}-$ $5^{\circ} \mathrm{S}, 120-170^{\circ} \mathrm{W}$; Trenberth, 1997) the well-known ENSOsensitive regions across eastern Australia, Indonesia, the Rio de la Plata delta, Argentina, and the south-west of the US are clearly indicated. Looking into the seasonal behaviour (bottom panel of Fig. 16), the well-known ENSO-sensitive areas across southern Africa and southeast China during northern hemispheric winter; the autumn and wintertime sensitive areas across the Amazon Basin, Venezuela and Guyana; and the south-west US being sensitive in autumn, winter and spring are well exposed. Even the narrow area along the Pacific coastline of Ecuador is well resolved. For the NAO-sensitive areas (Fig. 17) the typical north-south gradient from positive to negative correlation across Europe is well visible for the annual average and, in particular, during wintertime. Interestingly this analysis also exposes further regions worldwide where the attribution to NAO is less straightforward. The strength of both analyses lies in the fact that it is based on a purely observational data set and along a 110 -yr period, making the result accordingly reliable. GPCC will publish a thorough discussion of these regional sensitivities of precipitation in a separate paper.

The GPCC-FD product may also be applied for trend analysis despite its limited temporal data homogeneity: due to the GPCC's success in data acquisition, the data coverage (Figs. 1, 4, and 5) of the GPCC-FD product no longer features a strong inhomogeneity at the end of 1986, in contrast to preceding versions (e.g. Version 4, see Fig. 1). Notwithstanding the fact that a robust trend analysis requires the scrutiny of a comprehensive station data homogenization, as currently carried out for the HOMPRA data set, the GPCCFD product can also be applied for trend analysis if a method that is robust against inhomogeneities is applied. In doing so the method of Sen (1968) is utilized in the interpretation of Huxol (2007) while bearing in mind the inhomogeneity issue during interpretation of the results. A thorough trend analysis shall be provided in a separate paper; here we only show the 110 - and 55 -yr trends across the globe at $0.5^{\circ}$ resolution (Fig. 18) in terms of total sums of deviations from the median across the period. Only trends above 95-percent significance level according to a Mann-Kendall test are considered. Apparently the trend patterns shrink substantially 


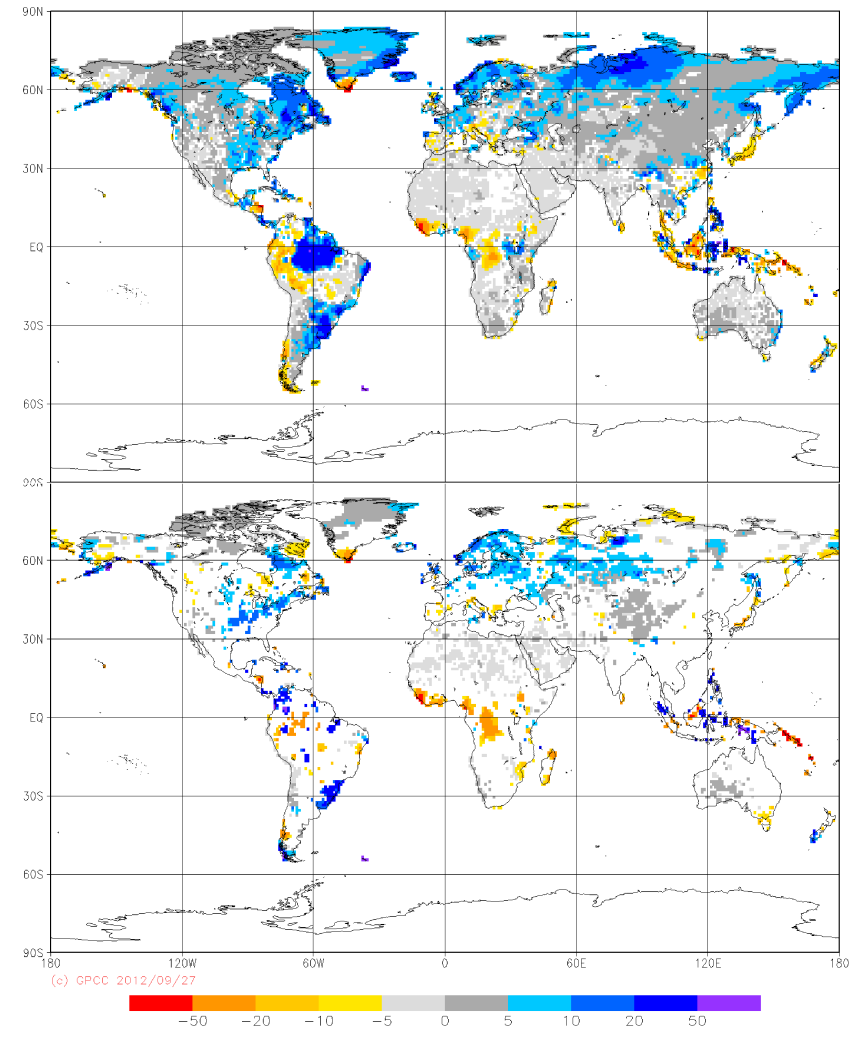

Figure 18. $110 \mathrm{yr}$ (January 1901-September 2011, top) and $55 \mathrm{yr}$ (January 1951-September 2011, bottom) total precipitation trends after Sen (in $\mathrm{mm}$ ) based on the GPCC-FD product at $0.5^{\circ}$ resolution. Regions without trends above $95 \%$ significance level and Antarctica are kept in white.

if only the most recent $55 \mathrm{yr}$ are considered, but certain regions with positive trends across eastern North America, northern Europe, the Rio de la Plata delta, and the western part of Siberia are clearly highlighted. Negative trends are strongest across the tropical western equatorial Africa. Despite the non-existence of a positive trend across northwestern Australia, these results identify the same regions for the annual trends as the VASClimO data set published by Beck et al. (2005).

\subsection{The GPCC Homogenized Precipitation Analysis (HOMPRA, for best homogeneity)}

While the GPCC-FD product involves all available stations with time series longer than $10 \mathrm{yr}$, this constraint is still not strong enough to warrant a data coverage that is stable across all times of multi-decadal or centennial studies of variability and trends of precipitation. Even if a longer time constraint is applied, the lack of homogeneity of long-term series of in situ precipitation observations remains a challenge to be met by appropriate detection and - if possible - correction to ultimately allow for a robust trend analysis. Currently the GPCC is developing its new Homogenized Precipitation Analysis
(HOMPRA) product that is based on a limited data collective of little more than 16350 stations that feature an above $90 \%$ availability of data across a 55-yr period from 1951-2005. For these stations, an automated version of the homogenization tool PRODIGE (Caussinus and Mestre, 2004; Mestre, 2004) developed by Rustemeier et al. (2012) is applied. Unfortunately the evaluation could not be finalized before the submission of this paper required to be done by 31 July 2012, to still be eligible for assessment by the authors writing the "Observations" chapter two of the WG-I part of the Fifth Assessment Report of the Intergovernmental Panel on Climate Change (IPCC). Therefore, our station-based trend analysis shown in Fig. 19 did not yet undergo the scrutiny and correction of Auto-PRODIGE. Notably, areas of positive trends match to a good extent those identified by the evaluation of the non-homogenized GPCC-FD product already. However, the positive trends across Northern Territory and across the Great Sandy Desert identified by the VASClimO analysis do not appear on the subset of the HOMPRA stations. Moreover, the cluster of stations with positive total trends for periods within 1951-2005 across the US (Fig. 19) covers a much larger area compared to the GPCC-FD-based trend analysis (Fig. 18) for periods 1901-2011 and 1951-2011, respectively. However, zooming into this area, as well as into Europe (not shown), reveals that besides the large-scale patterns (such as the north-south gradient of trends across Europe) there is a high variability of trends among stations located close to each other. This is a typical feature in particular across the mid-latitudes where the natural variability is high in both wind and precipitation, leading to very local effects in dependence of elevation, surrounding orography and exposition of each station. This can also induce inhomogeneity when stations are relocated. Only with completion of the HOMPRA data set a robust gridded trend analysis updating the VASClimO data set can be provided. For the time being, the user is referred to the VASClimO data set also provided through the GPCC products download gate. The access to all GPCC products is specified in the following Sect. 8 .

\section{Access to GPCC products and plots and user advice}

\subsection{Access methods}

The different gridded monthly precipitation data sets of GPCC, as well as the GPCP Version 2.1 satellite-gauge data set available at $2.5^{\circ}$ resolution for the period January 1979 until June 2009, have been published. They can be visualized in maps like Figs. 11 or 12 or downloaded in ASCII format using the GPCC-Visualizer integrated into the public GPCC website http://gpcc.dwd.de. Moreover the download pointers and DOIs listed in Sect. 1 apply. On ftp://ftp.dwd.de/pub/ data/gpcc/html/download_gate.html, GPCC has also implemented an ftp download gate pointing to all aforementioned 


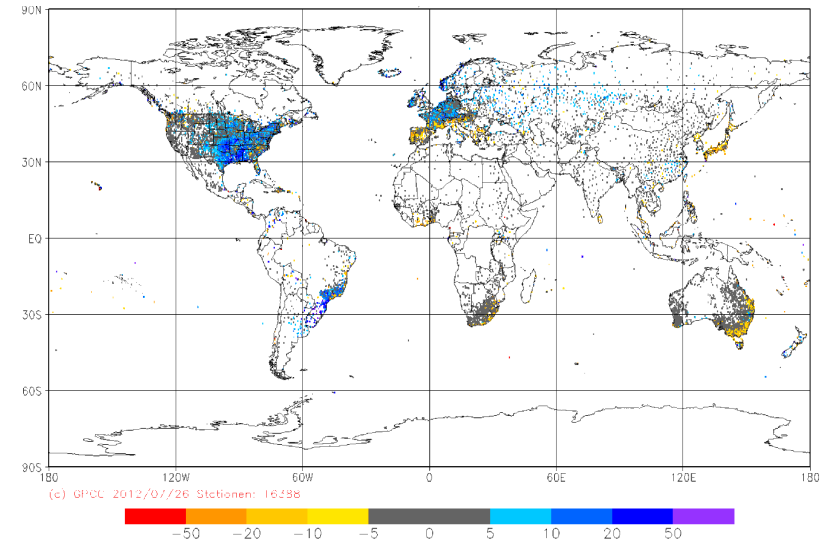

Figure 19. Total precipitation trends (Sen method) in $\mathrm{mm}$ for the 16388 stations chosen for the HOMPRA data set under development. These stations feature a $90 \%$ data coverage across the entire trend period regarded. Please note that the trend periods are stationspecific and can deviate from the HOMPRA period 1951-2005 in dependence of the data availability of each station.

products, the "GPCC Visualizer", and current documentation of each product, for the user's convenience.

\subsection{User advice}

The following should be considered when using GPCC gridded land-surface precipitation products:

- Check which product is most suitable for the application purpose with regard to the priority of timeliness, high availability and quality, accuracy, or homogeneity.

- Pay attention to the accuracy-related information provided by the GPCC (number of stations per grid, systematic error). Check the error range by consideration of the systematic error estimates and the regional number of stations used.

- Do not compare regional area-means which are calculated from data sets on different grid resolutions. The rough approximation of coastlines may cause relevant deviations between $2.5^{\circ}$ and $1.0^{\circ}$ based on area means. If you use standard software tools like the "fldmean" command of the climate data operators (Schulzweida et al., 2011), please note that they have their own approaches to consider the land-surface percentage that might differ from the GPCC one described in Sect. 4.2, thus yielding means that are potentially tool-specific.

- When analysing long-term climate variability and changes, do not combine different GPCC products available for different periods, which may cause discontinuities in time. Only a homogenized product like the HOMPRA product under development is fully adjusted to support long-term precipitation variability and trend analyses.
- For periods where both the FD V6 and the MP V4 product are available, rather refer to the FD product which is always based on more stations than the MP product. Only if you need to reproduce a GPCP product, reference to the MP product is meaningful.

- Reference to the GPCC through citations of this publication is requested from the users, and feedback about the application of the products to gpcc@dwd.de is very welcome.

\section{Conclusions}

Reference information on the most recent versions of the four gridded monthly observational data sets on the global gaugebased land-surface precipitation constructed and published by the Global Precipitation Climatology Centre (GPCC) is provided. Each of the four data set products is optimized for a specific purpose, where either best stability and representativeness, (Climatology Version 2011), high accuracy (Full Data Reanalysis Version 6), high availability and reasonable timeliness (Monitoring Product Version 4), or high timeliness (First Guess Product) are the major requirements. For all products, GPCC claims to serve the best possible observational gridded monthly land-surface precipitation data worldwide, as they all are fed by the worldwide largest database of quality-controlled rain gauge data collected from eight different sources, allowing for cross-checking of redundant data gathered from multiple sources.

With the digital object identifiers (DOIs) issued for each product and spatial resolution of the gridded data sets, we hope to have provided a repository of high-quality gridded precipitation analyses across the past $110 \mathrm{yr}$ from present back to year 1901, for the general public as well as for the scientific user community including the authors of the Fifth Assessment Report of the IPCC. The data sets are accompanied by all essential information on their genesis and the corresponding ISO compliant metadata. All gridded products of the GPCC are provided through a download gateway under ftp://ftp.dwd.de/pub/data/gpcc/html/download_gate.html hosted permanently by the Deutscher Wetterdienst.

Utilization examples of the GPCC products encompass case studies of specific events in the near or long-term past, identification of ENSO- and NAO-sensitive precipitation regions, and trend analysis across periods that can be chosen to up to $110 \mathrm{yr}$ in length starting from 1901. Moreover, the GPCC suite of documented gridded products establishes a homogeneous reference database for model validation and cross-comparison and calibration with non-in-situ-based data sets.

\section{Outlook}

A fifth product optimized for homogeneity is still in preparation; thus its predecessor VASClimO V1.1, thoroughly 
utilized for the Fourth Assessment Report, remains a recommended reference and is also available through the aforementioned GPCC download gateway. The replacement product HOMPRA (Homogenized Precipitation Analysis) will be superior in terms of the number of supporting stations that is effectively doubled (given the too high density of stations across central Europe for VASClimO) and the homogenization methodology utilized. The publication of HOMPRA is scheduled for 2013.

Since 2011, GPCC has also commenced analysis of daily precipitation within an effort to combine a daily version of the HOAPS-3 product (HOAPS-4) with a daily GPCC precipitation analysis. First prototype results are expected to become available in 2013, but providing a purely observational gridded daily data product at a reasonable quality and reliability remains a challenge. A major prerequisite for future enhancements on daily products lies in the successful data acquisition, as the demand on the station number and density is much higher for daily data.

\section{Appendix A}

\section{Abbreviations}

\begin{tabular}{|c|c|}
\hline ASCII & $\begin{array}{l}\text { American Standard Code for Information } \\
\text { Interchange }\end{array}$ \\
\hline CLIMAT & The pendant code to SYNOP for monthly records \\
\hline CMAP & The CPC Merged Analysis of Precipitation \\
\hline $\mathrm{CPC}$ & Climate Prediction Center \\
\hline CRU & $\begin{array}{l}\text { Climate Research Unit (of the University of East } \\
\text { Anglia in Norwich, UK) }\end{array}$ \\
\hline DOI & Digital object identifier \\
\hline DWD & Deutscher Wetterdienst \\
\hline $\mathrm{ECV}$ & Essential climate variable \\
\hline ENSO & El Niño-Southern Oscillation \\
\hline ERA-CLIM & $\begin{array}{l}\text { European Reanalysis of Global Climate } \\
\text { Observations }\end{array}$ \\
\hline FAO & $\begin{array}{l}\text { Food and Agriculture Organization } \\
\text { (of the United Nations) }\end{array}$ \\
\hline GCOS & Global Climate Observing System \\
\hline GEWEX & $\begin{array}{l}\text { Global Energy and Water Cycle Experiment } \\
\text { (now Global Energy and Water Exchanges) }\end{array}$ \\
\hline $\mathrm{GHCN}$ & $\begin{array}{l}\text { Global Historical Climatology Network } \\
\text { (of NOAA NCDC) }\end{array}$ \\
\hline GHCN & Global Historical Climatology Network \\
\hline GPCC-CLIM & GPCC Climatology Product \\
\hline GPCC-FD & GPCC Full Data Product \\
\hline GPCC-FG & GPCC First Guess Product \\
\hline GPCC-HOM & GPCC HOMPRA Product \\
\hline GPCC-MP & GPCC Monitoring Product \\
\hline GPCP & $\begin{array}{l}\text { Global Precipitation Climatology } \\
\text { Project }\end{array}$ \\
\hline
\end{tabular}

\begin{tabular}{|c|c|}
\hline GTOPO-30 & $\begin{array}{l}\text { Global } 30 \text { Arc Second Elevation Data Set of US } \\
\text { Geological Survey }\end{array}$ \\
\hline GTS & Global Telecommunication System (of WMO) \\
\hline HOAPS & $\begin{array}{l}\text { Hamburg Ocean Atmosphere Parameters and } \\
\text { Fluxes from Satellite Data }\end{array}$ \\
\hline HOMPRA & Homogenized Precipitation Analysis \\
\hline IPCC & Intergovernmental Panel on Climate Change \\
\hline ISO & $\begin{array}{l}\text { International Organization for Standardization, } \\
\text { www.iso.org }\end{array}$ \\
\hline MAE & Mean absolute error \\
\hline NAO & North Atlantic Oscillation \\
\hline $\mathrm{NCDC}$ & National Climate Data Center (of NOAA) \\
\hline NHMS & $\begin{array}{l}\text { National Hydro- and Meteorological Service } \\
\text { (of WMO) }\end{array}$ \\
\hline NOAA & $\begin{array}{l}\text { National Oceanic and Atmospheric } \\
\text { Administration }\end{array}$ \\
\hline PEHRP & $\begin{array}{l}\text { Pilot Evaluation of High Resolution Precipitation } \\
\text { Products }\end{array}$ \\
\hline QC & Quality control \\
\hline RA & Regional Association (of WMO) \\
\hline RDBMS & Relational database management system \\
\hline RRR & $\begin{array}{l}\text { Precipitation total in mm reported in the } \\
\text { precipitation group of a SYNOP message }\end{array}$ \\
\hline RRRR & $\begin{array}{l}\text { Precipitation total in mm reported in the } \\
\text { precipitation group of a CLIMAT message }\end{array}$ \\
\hline SOI & (El Niño) Southern Oscillation Index \\
\hline SPHEREMAP & $\begin{array}{l}\text { Spherical adaptation of Shepard's interpolation } \\
\text { method (Willmott et al., 1985) }\end{array}$ \\
\hline SYNOP & $\begin{array}{l}\text { Abbreviation for surface synoptic observations } \\
\text { encoded in SYNOP Data Format (FM-12) detailed } \\
\text { on http://weather.unisys.com/wxp/Appendices/ } \\
\text { Formats/SYNOP.html }\end{array}$ \\
\hline VASClimO & $\begin{array}{l}\text { Variability Analysis of Surface Climate } \\
\text { Observations }\end{array}$ \\
\hline WCRP & World Climate Research Project (of WMO) \\
\hline WMO & World Meteorological Organization \\
\hline ww & The present weather group of a SYNOP message \\
\hline WW & The past weather group of a SYNOP message \\
\hline
\end{tabular}

\section{Appendix B}

\section{List of contributions to GPCC from national and regional suppliers}

Below, the 230 potential and actual contributors of original data from suppliers of running gauge networks are listed. The list comprises the 158 WMO NHMSs and 31 regional suppliers that actually have supplied data to the GPCC at least once. The total data period covered is indicated for each contributor $(\mathrm{T})$ followed by an ad hoc indicator rating the network density $(\mathrm{S}=$ superior, $\mathrm{G}=$ good, $\mathrm{H}=$ half sufficient, $\mathrm{M}=$ minor number of stations). The first and last 
years of data available at the indicated network density are also provided for every record. Finally, a "*” indicates if the data have arrived at GPCC through a scientific project instead of an official bilateral contact to the country or region regarded. Countries and regions without any time entry have not yet supplied data to GPCC; hence GPCC would particularly welcome their initial supplies, as well as updates from the other contributors. It should be noted that GTS-connected stations are not considered in this list, although their screened data are also processed for all GPCC products. Therefore the universalization of the GPCC data coverage is even higher than listed below and permanently growing.

\begin{tabular}{|c|c|}
\hline Afghanistan & H: 1976-1980 TM: 1958-1984 \\
\hline Alaska (USA) & TH: $1986-2000$ \\
\hline Albania & S: 1986-2000 TG: 1951-2008 \\
\hline Algeria & TM: 1936-2005 \\
\hline American Samoa (USA) & TS: 1986-2000 \\
\hline \multicolumn{2}{|l|}{ Andorra } \\
\hline Angola & TM: 1901-2006 \\
\hline \multicolumn{2}{|l|}{ Anguilla } \\
\hline \multicolumn{2}{|l|}{ Antarctica } \\
\hline \multicolumn{2}{|l|}{ Antigua and Barbuda } \\
\hline Argentina & TM: 1861-2008 \\
\hline Armenia & G: 1986-2000 TH: 1931-2005 \\
\hline \multicolumn{2}{|l|}{ Atlantic Ocean islands } \\
\hline Australia & TS: 1850-2008 \\
\hline Austria & S: 1936-2011 TH: 1900-2011 \\
\hline Azerbaijan & TH: 1989-1993 \\
\hline Azores (Port.) & TS: 1986-1996 \\
\hline Bahamas & TS: $1971-2000$ \\
\hline Bahrain & TS: $1948-2009$ \\
\hline Bangladesh & TH: 1948-2008 \\
\hline Barbados & TS: 1968-2004 \\
\hline Belarus & TG: 1961-2008 \\
\hline Belgium & S: 1986-2008 TH: 1951-2008 \\
\hline Belize & TS: 1960-2004 \\
\hline Benin & TS: 1951-2005 \\
\hline \multicolumn{2}{|l|}{ Bermuda } \\
\hline Bhutan & TS: 1990-2009 \\
\hline Bolivia & TM: 1942-2009 \\
\hline Bosnia and Herzegovina & S: 1951-1991 TM: 1888-2001 \\
\hline Botswana & TM: 1981-2009 \\
\hline Brazil & H: 1986-1999 TM: 1950-2004 \\
\hline Brunei & TH: 1986-1996 \\
\hline Bulgaria & G: 1986-2006 TM: 1931-2006 \\
\hline Burkina Faso* & TS: 1902-2000 \\
\hline Burundi & TG: 1986-1993 \\
\hline Cambodia* & TM: 1907-2001 \\
\hline Cameroon & TM: 1960-1997 \\
\hline Canada & TG: 1840-2009 \\
\hline Canary Islands (Spain) & TG: 1986-1998 \\
\hline Cape Verde & TH: 1950-2003 \\
\hline \multicolumn{2}{|l|}{ Cayman Islands } \\
\hline \multicolumn{2}{|l|}{ Central African Republic } \\
\hline Chad & \\
\hline
\end{tabular}

\begin{tabular}{|c|c|}
\hline Chile & TS: 1970-2007 \\
\hline China & TM: 1951-2010 \\
\hline Colombia & S: 2001-2005 TM: 1910-2009 \\
\hline Comoros & TG: $1987-1993$ \\
\hline \multicolumn{2}{|l|}{ Congo } \\
\hline Cook Islands (New Zealand) & TS: 1986-1996 \\
\hline Costa Rica & TM: 1888-2011 \\
\hline Côte d'Ivoire & TS: $1905-2000$ \\
\hline Croatia & TM: 1862-2005 \\
\hline Cuba & TG: $1986-1993$ \\
\hline Cyprus & S: 1986-1990 TG: 1925-2011 \\
\hline Czech Republic & TS: 1961-2011 \\
\hline \multicolumn{2}{|l|}{ DR Congo (former Zaire) } \\
\hline Denmark & S: 1961-2012 TH: 1860-2012 \\
\hline Djibouti & TM: 1986-1998 \\
\hline \multicolumn{2}{|l|}{ Dominica } \\
\hline Dominican Republic & TS: $1931-2010$ \\
\hline Ecuador & S: 1976-2003 TM: 1901-2008 \\
\hline Egypt & H: 1986-1996 TM: 1968-2008 \\
\hline El Salvador & G: 1986-1993 TM: 1971-2008 \\
\hline \multicolumn{2}{|l|}{ Equatorial Guinea } \\
\hline Eritrea & TM: 1986-2000 \\
\hline Estonia & TH: 1986-2001 \\
\hline Ethiopia & TM: 1951-2008 \\
\hline Falacep Island (USA) & TG: $1989-2000$ \\
\hline \multicolumn{2}{|l|}{ Falkland Islands } \\
\hline \multicolumn{2}{|l|}{ Faroe Islands } \\
\hline Fiji & TS: $1986-1998$ \\
\hline Finland & TS: 1961-2005 \\
\hline France & TS: 1819-2010 \\
\hline \multicolumn{2}{|l|}{ French Guyana } \\
\hline French Polynesia (via N. Zeal.) & TS: 1989 \\
\hline Gabon & TM: 1950-2000 \\
\hline \multicolumn{2}{|l|}{ Gambia } \\
\hline Georgia & S: $1936-1990$ TM: $1844-2010$ \\
\hline Germany & TS: 1840-2012 \\
\hline Ghana* & TM: 1944-2010 \\
\hline \multicolumn{2}{|l|}{ Gibraltar } \\
\hline Greece & TH: 1911-2010 \\
\hline Greenland & TM: 1860-2004 \\
\hline \multicolumn{2}{|l|}{ Grenada } \\
\hline \multicolumn{2}{|l|}{ Guadeloupe } \\
\hline Guam (USA) & TS: $1986-2000$ \\
\hline Guatemala & TH: 1980-1992 \\
\hline Guinea & TM: 1903-2003 \\
\hline Guinea-Bissau & S: $1950-2005$ TG: $1924-2011$ \\
\hline Guyana & S: 1995-2006 TM: 1950-2006 \\
\hline \multicolumn{2}{|r|}{ (1) } \\
\hline Hawaii (USA) & TS: 1986-2000 \\
\hline Honduras & TM: 1944-1993 \\
\hline Hong Kong & TS: 1884-2011 \\
\hline Hungary & TS: $1951-2010$ \\
\hline Iceland & TS: 1924-2007 \\
\hline India & TM: 1961-2000 \\
\hline \multicolumn{2}{|l|}{ Indian Ocean islands } \\
\hline Indonesia & TM: 1979-1999 \\
\hline Iran & S: 1986-2005 TM: 1951-2008 \\
\hline Iraq & H: $1939-1958$ TM: $1887-1958$ \\
\hline Ireland & TS: 1986-1995 \\
\hline Israel & TG: 1986-2007 \\
\hline Italy & S: 1986-1991 TG: 1951-2011 \\
\hline
\end{tabular}




\begin{tabular}{|c|c|}
\hline \multicolumn{2}{|l|}{ Jamaica } \\
\hline Japan & TG: 1863-2010 \\
\hline Johnston Islands (USA) & TS: 1986-2000 \\
\hline Jordan & S: 1986-1999 TM: 1985-2004 \\
\hline Kazakhstan & TG: 1881-2006 \\
\hline Kenya & TS: $1969-1990$ \\
\hline Kiribati (via New Zealand) & TG: 1989-1996 \\
\hline Korea, North & H: 1954-2003 TM: 1905-2003 \\
\hline Korea, South & TS: 1951-2008 \\
\hline \multicolumn{2}{|l|}{ Kuwait } \\
\hline Kyrgyzstan & TG: 1889-2007 \\
\hline \multicolumn{2}{|l|}{ Laos } \\
\hline Latvia & H: 1986-2011 TM: 1901-2011 \\
\hline \multicolumn{2}{|r|}{ 1.. 1. } \\
\hline \multicolumn{2}{|l|}{ Lesotho } \\
\hline \multicolumn{2}{|l|}{ Liberia } \\
\hline Libya & TG: 1986-1992 \\
\hline Liechtenstein & TG: 1986-2003 \\
\hline Lithuania & TH: 1922-2010 \\
\hline Luxembourg & TS: 1949-2006 \\
\hline Macau & TG: 1901-2010 \\
\hline Macedonia & TH: 1986-2002 \\
\hline \multicolumn{2}{|l|}{ Madagascar } \\
\hline Madeira (Port.) & TS: 1986-1996 \\
\hline Malawi & G: 1960-2004 TM: 1901-2004 \\
\hline Malaysia & S: $1986-1993$ TM: $1951-2008$ \\
\hline Maldives & TS: 1974-2008 \\
\hline Mali & S: 1987-1988 TG: 1987-1991 \\
\hline Malta & TG: 1922-2007 \\
\hline Mariana Islands (USA) & TS: $1987-2000$ \\
\hline Marshall Islands (USA) & TS: $1986-2000$ \\
\hline \multicolumn{2}{|l|}{ Martinique } \\
\hline \multicolumn{2}{|l|}{ Mauritania } \\
\hline Mauritius & TS: 1986-2008 \\
\hline Mexico & H: 1986-1989 TM: 1893-2005 \\
\hline Micronesia (via USA) & TS: 1986-2000 \\
\hline \multicolumn{2}{|l|}{ Midway Island } \\
\hline Moldova & TS: $1986-1998$ \\
\hline \multicolumn{2}{|l|}{ Monaco } \\
\hline Mongolia & H: 1937-2008 \\
\hline Morocco & TM: $1920-2007$ \\
\hline Mozambique & TH: 1951-2008 \\
\hline Myanmar & TM: 1965-2003 \\
\hline Namibia & H: 1952-2008 TM: 1890-1993 \\
\hline \multicolumn{2}{|l|}{ Nauru } \\
\hline Nepal & TS: 1947-2007 \\
\hline Netherlands Antilles & TS: $1970-1993$ \\
\hline Netherlands & TS: 1951-2011 \\
\hline \multicolumn{2}{|l|}{ New Caledonia } \\
\hline New Zealand & S: 1986-2010 TM: 1873-2011 \\
\hline Nicaragua & TG: 1952-2004 \\
\hline Niger & G: $1981-1991$ TM: $1905-2008$ \\
\hline Nigeria & TM: 1961-1997 \\
\hline Norway & TS: $1950-2008$ \\
\hline Oman & S: $1986-1992$ TM: $1942-2008$ \\
\hline Pakistan & TM: 1961-2007 \\
\hline Palau (via USA) & TS: 1986-2000 \\
\hline Panama & TS: $1955-2008$ \\
\hline \multicolumn{2}{|l|}{ Papua New Guinea } \\
\hline Paraguay & TM: 1986-1998 \\
\hline Peru & S: $1964-2005$ TM: $1931-2006$ \\
\hline Philippines & TM: 1902-2004 \\
\hline Pitcairn, BOT (via New Zealand) & TG: 1993-1996 \\
\hline
\end{tabular}

\begin{tabular}{|c|c|}
\hline Poland & G: 1986-2011 TM: 1951-2011 \\
\hline Portugal & TS: 1951-2010 \\
\hline Puerto Rico (USA) & TS: 1986-2000 \\
\hline Qatar & S: 1986-1993 TM: 1962-2003 \\
\hline Romania & TS: 1961-2004 \\
\hline Russia & TM: 1966-2009 \\
\hline Rwanda & S: $1965-1991$ TG: $1926-1991$ \\
\hline \multicolumn{2}{|l|}{ Saint Kitts and Nevis } \\
\hline Sweden & TS: 1961-2003 \\
\hline Switzerland & TS: 1864-2011 \\
\hline Syria & H: 1986-1992 TM: 1946-2004 \\
\hline \multicolumn{2}{|l|}{ Saint Lucia } \\
\hline \multicolumn{2}{|l|}{ Saint Vincent } \\
\hline \multicolumn{2}{|l|}{ San Marino } \\
\hline \multicolumn{2}{|l|}{ Sao Tome and Principe } \\
\hline \multicolumn{2}{|l|}{ Saudi Arabia } \\
\hline \multicolumn{2}{|l|}{ Senegal } \\
\hline Seychelles & TS: 1971-2010 \\
\hline \multicolumn{2}{|l|}{ Sierra Leone } \\
\hline \multicolumn{2}{|l|}{ Singapore } \\
\hline Slovakia & TS: 1901-2011 \\
\hline Slovenia & TS: $1951-2009$ \\
\hline Solomon Islands & TS: 1989-1996 \\
\hline \multicolumn{2}{|l|}{ Somalia } \\
\hline South Africa & TS: 1951-2008 \\
\hline Spain & TS: $1900-2003$ \\
\hline Sri Lanka & TG: 1986-1995 \\
\hline Sudan & TM: 1902-2004 \\
\hline Suriname & TM: $1852-2009$ \\
\hline Swaziland & S: 1919-1992 TM: 1897-1993 \\
\hline Taiwan & TG: 1935-2011; 1897-2011 \\
\hline \multicolumn{2}{|l|}{ Tajikistan } \\
\hline Tanzania & TM: 1961-2006 \\
\hline Thailand & TH: 1951-2009 \\
\hline Togo & TS: 1901-2005 \\
\hline Tokelau (New Zealand) & TS: 1989-1996 \\
\hline Tonga (via New Zealand) & TS: $1989-1996$ \\
\hline Trinidad \& Tobago & TG: 1986-1995 \\
\hline Tunisia & TG: 1986-1999 \\
\hline Turkey & G: 1961-2007 TM: 1846-2007 \\
\hline Turkmenistan & TM: 1986-1990 \\
\hline \multicolumn{2}{|l|}{ Turks and Caicos Islands } \\
\hline Tuvalu (via New Zealand) & TG: 1989-1996 \\
\hline Uganda & TM: 1951-2008 \\
\hline Ukraine & H: 1986-1992 TM: 1885-2009 \\
\hline United Arab Emirates & H: 1980-2000 TM: 1974-2008 \\
\hline United Kingdom & S: $1961-2011$ TM: $1853-2011$ \\
\hline Uruguay & TM: 1961-2004 \\
\hline USA & TS: $1878-2007$ \\
\hline Uzbekistan & TM: 1879-2010 \\
\hline Vanuatu (via New Zealand) & TG: 1952-2010 \\
\hline Venezuela & S: $1968-1996$ TM: $1901-2005$ \\
\hline Vietnam & S: $1959-1983$ TM: 1886-2008 \\
\hline \multicolumn{2}{|l|}{ Virgin Islands (GB) } \\
\hline Virgin Islands (USA) & TS: 1986-2000 \\
\hline Wake Island (USA) & TS: $1986-2000$ \\
\hline \multicolumn{2}{|l|}{ Wallis and Futuna } \\
\hline Western Sahara & TM: 1986-1989 \\
\hline Samoa (via New Zealand) & TG: 1989-1994 \\
\hline Yemen & TM: 1995-2005 \\
\hline Serbia + Montenegro & TH: 1961-2004 \\
\hline Zambia & TM: 1933-2011 \\
\hline Zimbabwe & TG: 1986-1994 \\
\hline
\end{tabular}




\section{Appendix C}

\section{Regional data sets available to GPCC}

We call data contributions with rain gauge data from specific regions "regional data sets". The current GPCC collection encompasses regional data sets for the former Soviet Union (Groisman et al., 1991; Groisman and Rankova, 2001) with data from 2186 stations for the period 1891-2001, updated to 2009 by a data set comprising 518 Russian stations (available from http://meteo.ru/english/climate/precip. php) described by Bulygina et al. (2010). Moreover, the African rainfall archive from Nicholson (1986, 1993, 2008) containing data of 1338 stations for the period up to 1998 with some time series starting as early as 1838 has been utilized for the GPCC products. Finally, since commencement of daily precipitation data analysis in early 2011, aggregation of monthly values from the GHCN-Daily data set (Menne et al., 2012) have been an on-going activity at GPCC, and accomplishments by December 2011 have been included in the GPCC-CLIM and GPCC-FD products.

Acknowledgements. First of all we are most appreciative to the data suppliers that are to the largest extent the worldwide spread National Meteorological and/or Hydrological Services but also some other institutes. Moreover Sharon Nicolson and Pavel ("Pasha") Groisman are acknowledged explicitly for making their unique and precious data collections available. It is only these data contributions that in total have put GPCC into the position to provide the global precipitation analyses described in this document, and we are looking forward to their further contributions, which are crucial to maintain and enhance GPCC's level of products in terms of scope and quality.

We are grateful for the contribution of Hermann Österle, Potsdam Institute for Climate Impact (PIK), who has de facto served as beta tester of Versions 4 and 5 of the Full Data Product, while checking them for the existence of inhomogeneities. His work has substantially supported the quality control and improvement of the GPCC products.

We are also grateful to colleagues from Deutscher Wetterdienst, namely Hermann Mächel for sharing his expertise in data analysis and quality control, Peter Stender for administration of the data acquisition, and Tanja Winterrath and Alexander Mazurkiewicz for their thorough reviews of the manuscript.

Finally we are grateful to the anonymous referees and the handling editor for provision of constructive and useful reviews and advice that have led to a substantially improved revised manuscript.

Edited by: F. Huettmann

\section{References}

Adler, R. F., Huffman, G. J., Chang, A., Ferraro, R., Xie, P.-P., Janowiak, J., Rudolf, B., Schneider, U., Curtis, S., Bolvin, D., Gruber, A., Susskind, J., Arkin, P., and Nelkin, E.: The Version-2 Global Precipitation Climatology Project (GPCP) Monthly Precipitation analysis (1979-present), J. Hydrometeorol., 4, 11471167, 2003.

Andersson, A., Fennig, K., Klepp, C., Bakan, S., Graß1, H., and Schulz, J.: The Hamburg Ocean Atmosphere Parameters and Fluxes from Satellite Data - HOAPS-3, Earth Syst. Sci. Data, 2, 215-234, doi:10.5194/essd-2-215-2010, 2010.

Arkin, P., Turk, J., and Ebert, B.: Pilot Evaluation of High Resolution Precipitation Products (PEHRPP): A Contribution to GPM Planning, http://www.eorc.jaxa.jp/GPM/event/ws5/hp/ en/materials/6.8.3_abstract_Arkin.pdf (last access: 11 January 2013), 2005.

Barrett, E. C., Doodge, J., Goodman, M., Janowiak, J., Smith, E., and Kidd, C.: The FirstWetNet Precipitation Intercomparison Project (PIP-1), Remote Sensing Review, 11, 49-60, 1994.

Beck, C., Grieser, J., and Rudolf, B.: A New Monthly Precipitation Climatology for the Global Land Areas for the Period 1951 to 2000, Climate status report, 2004, 181-190, http://www.dwd. de/bvbw/generator/DWDWWW/Content/Oeffentlichkeit/KU/ $\mathrm{KU} 4 / \mathrm{KU} 42 /$ en/VASClimO/pdf__28_-precipitation,templateId= raw,property=publicationFile.pdf/pdf_28_precipitation.pdf (last access: 11 January 2013), 2005.

Bulygina, O. N., Razuvaev, V. N., Korshunova, N. N., and Shvets, N. V.: Description of dataset of monthly precipitation totals from Russian stations, Internet Publication available from http: //meteo.ru/english/climate/descrip7.htm (last access: 11 January 2013), 2010.

Bussieres, N. and Hogg, W.: The objective analysis of daily rainfall by distance weighting schemes on a mesoscale grid, Atmos. Ocean, 27, 521-541, 1989.

Caussinus, H. and Mestre, O.: Detection and correction of artificial shifts in climate series, J. Roy. Stat. Soc. C-App., 53, 405-425, 2004.

Chen, M. P., Xie, P., Janowiak, J. E., and Arkin, P. A.: Global land precipitation: A 50-year monthly analysis based on gauge observations, J. Hydrometeorol., 3, 249-266, 2002.

Dai, A., Fung, I. Y., and Del Genio, A. D.: Surface observed global land precipitation variations during 1900-1988, J. Climate, 10, 2943-2962, 1997.

Dee, D. P., Uppala, S. M., Simmons, A. J., Berrisford, P., Poli, P., Kobayashi, S., Andrae, U., Balmaseda, M. A., Balsamo, G., Bauer, P., Bechtold, P., Beljaars, A. C. M., van de Berg, L., Bidlot, J., Bormann, N., Delsol, C., Dragani, R., Fuentes, M., Geer, A. J., Haimberger, L., Healy, S. B., Hersbach, H. , Hólm, E. V., Isaksen, L., Kållberg, P., Köhler, M., Matricardi, M., McNally, A. P., Monge-Sanz, B. M., Morcrette, J.-J., Park, B.-K., Peubey, C., de Rosnay, P., Tavolato, C., Thépaut, J.-N., and Vitart, F.: The ERA-Interim reanalysis: configuration and performance of the data assimilation system, Q. J. Roy. Meteorol. Soc., 137, 553597, 2011.

Dinku, T., Connor, S. J., Ceccato, P., and Ropelewski, C. F.: Comparison of global gridded precipitation products over a mountainous region of Africa, Int. J. Climatol., 28, 1627-1638, 2008. 
Ebert, E. E., Janowiak, J., and Kidd, C.: Comparison of near-realtime precipitation estimates from satellite observations and numerical models, B. Am. Meteorol. Soc., 88, 47-64, 2007.

FAO: FAOClim 2.0. A world-wide agroclimatic database. Food and Agriculture Organization of the UN, Rome, Italy, CDROM + Users Manual (72 pp.) Environment and Natural Resources Working paper No. 5, available at: http://www.fao.org/ nr/climpag/pub/en1102_en.asp (last access: 11 January 2013), 2001.

FAO: http://www.fao.org/nr/climpag/hot_2_en.asp (last access: 11 January 2013), 2011.

Fuchs, T., Rapp, J., Rubel, F., and Rudolf, B.: Correction of Synoptic Precipitation Observations due to Systematic Measuring Errors with Special Regard to Precipitation Phases, Phys. Chem. Earth Pt. B, 26, 689-693, 2001.

GCOS: Implementation Plan for the Global Observing System for Climate in Support of the UNFCCC, 186 pp., http://www.wmo. int/pages/prog/gcos/Publications/gcos-138.pdf (last access: 11 January 2013), 2010.

GCOS: Summary Report and Recommendations from the Sixteenth Session of the GCOS/WCRP Atmospheric Observation Panel for Climate (AOPC-XVI), http://www.wmo.int/pages/prog/gcos/ Publications/gcos-148.pdf (last access: 11 January 2013), 2011.

Goodison, B. E., Louie, P. Y. T., and Yang, D.: WMO solid precipitation measurement inter-comparison - final report; WMO/TDNo. 872; Instruments and Observing Methods Report No. 67, WMO, Geneva, Switzerland, 212 pp., http://www.wmo.int/ pages/prog/www/reports/WMOtd872.pdf (last access: 11 January 2013), 1998.

Groisman, P. Y. and Rankova, E. Y.: Precipitation trends over the Russian permafrost-free zone: removing the artefacts of preprocessing, Int. J. Climatol., 21, 658-678, 2001.

Groisman, P. Y., Koknaeva, V. V., Belokrylova, T. A., and Karl, T. R.: Overcoming biases of precipitation measurement: A history of the USSR experience, B. Am. Meteorol. Soc., 72, 1725-1733, 1991.

Gruber, A. and Levizzani, V.: Assessment of Global Precipitation, A Project of the Global Energy and Water Cycle Experiment (GEWEX) Radiation Panel GEWEX, World Climate Research Program, WCRP Report, WMO/TD-No. 1430, WMO Geneva, Switzerland, p. 5, 2008.

Hennon, P., Kruk, M., Hiburn, K., Yin, X., and Becker, A.: Global Climate Precipitation, in: State of the Climate in 2010, B. Am. Meteor. Soc., 92, 161-163, 2011.

Hijmans, R. J., Cameron, S. E., Parra, J. L., Jones, P. G., and Jarvis, A.: Very high resolution interpolated climate surfaces for global land areas, Int. J. Climatol., 25, 1965-1978, 2005.

Hofstra, N., Haylock, M., New, M., Jones, P., and Frei, C.: Comparison of six methods for the interpolation of daily, European climate data, J. Geophys. Res., 113, D21110, doi:10.1029/2008JD010100, 2008.

Hou, A. Y., Skofronick-Jackson, G., Kummerow, C., and Shepherd, J. M.: Global Precipitation Measurement, in: Precipitation: Advances in Measurement, Estimation and Prediction, edited by: Michaelides, S., Springer-Verlag, 540 pp., ISBN 978-3-54077654-3, 2008.

Huffman, G. J., Adler, R. F., Rudolf, B., Schneider, U., and Keehn, P. R.: Global precipitation estimates based on a technique for combining satellite- based estimates, rain gauge analysis, and
NWP model precipitation information, J. Climate, 8, 1284-1295, 1995.

Huffman, G. J., Adler, R. F., Bolvin, D. T., and Gu, G.: Improving the global precipitation record: GPCP Version 2.1, Geophys. Res. Lett., 36, L17808, doi:10.1029/2009GL040000, 2009.

Huxol, S.: Trendanalyse von Zeitreihen der Komponenten des Wasserkreislaufes im Einzugsgebiet der Dreisam zur prozessorientierten Beurteilung hydrologischer Klimafolgen, Diploma Thesis, Institut for Hydrology at the Albert-Ludwigs-University Freiburg i.Br., Germany, http://www.hydrology.uni-freiburg.de/ abschluss/Huxol_S_2007_DA.pdf (last access: 11 January 2013), 2007.

Jenne, R. and Joseph, D.: Sensitivity experiments with different 1 to $500 \mathrm{~km}$ scale networks (NCAR), WMO/TD-No. 115, Geneva, Switzerland, 1985.

Kaspar, F. and Cubasch, U.: Simulation of East African precipitation patterns, Meteorol. Z., 17, 511-517, 2008.

Kidd, C. and Huffman, G.: Review Global precipitation measurement, Meteorol. Appl., 18, 334-351, http://onlinelibrary.wiley. com/doi/10.1002/met.284/pdf, 2011.

Kidd, C., Ferraro, R., and Levizzani, V.: The International Precipitation Working Group, B. Am. Meteorol. Soc., 8, 1095-1099, doi:10.1175/2009BAMS2871.1, 2010.

Kidd, C., Bauer, P., Turk, J., Huffman, G., Joyce, R., Hsu, K.-L., and Braithwaite, D.: Inter-comparison of High-Resolution Precipitation Products over Northwest Europe, J. Hydrometeorol., 13, 67-83, doi:10.1175/JHM-D-11-042.1, 2012.

Kottek, M. and Rubel, F.: Global daily precipitation field from biascorrected rain gauge and satellite observations. Part I: Design and Development, Meteorol. Z., 16, 525-539, 2007.

Krige, D. G.: A statistical approach to some basic mine valuation problems on the Witwatersrand, Journal of the Chemical, Metallurgical and Mining Society of South Africa, 52, 119-139, 1951.

Legates, D. R.: A climatology of global precipitation, Publ. in Climatology, 40, 85 pp., 1987.

Legates, D. R. and Willmott, C. J.: Mean seasonal and spatial variability in gauge-corrected, global precipitation, Int. J. Climatol., 10, 111-127, 1990.

Mächel, H., Rudolf, B., Maurer, T., Hagemann, S., Hagenbrock, R., Kitaev, L., Førland, E. J., Rasuvaev, V., and Tveito, I. E.: Chapter 5: Observed Hydrological Cycle, in: Arctic Climate Change, edited by: Lemke, P. and Jacobi, H.-W., Springer Dordrecht Heidelberg London New York, ISSN 1381-8601, ISBN 97894-0072026-8, doi:10.1007/978-94-007-2027-5, 464 pp., 2012.

Matsuura, K. and Willmott, C. J.: Terrestrial Precipitation: 1900-2010 Gridded Monthly Time Series (Version 3.01), http://climate.geog.udel.edu/ climate/html_pages/Global2011/ README.GlobalTsP2011.html (last access: 11 January 2013), 2012.

Menne, M. J., Durre, I., Vose, R. S., Gleason, B. E., and Houston, T. G.: An Overview of the Global Historical Climatology NetworkDaily Database, J. Atmos. Ocean. Tech., 29, 897-910, 2012.

Mestre, O.: Correcting climate series using ANOVA technique, Proceedings of the Fourth Seminar for Homogenization and Quality Control in Climatological Databases, Budapest, Hungary, 93-96, 2004.

Meyer-Christoffer, A., Becker, A., Finger, P., Rudolf, B., Schneider, U., and Ziese, M.: GPCC Climatology Version 2011 at $0.25^{\circ}$ : Monthly Land-Surface Precipitation 
Climatology for Every Month and the Total Year from Rain-Gauges built on GTS-based and Historic Data, doi:10.5676/DWD_GPCC/CLIM_M_V2011_025, 2011a.

Meyer-Christoffer, A., Becker, A., Finger, P., Rudolf, B., Schneider, U., and Ziese, M.: GPCC Climatology Version 2011 at $0.5^{\circ}$ : Monthly Land-Surface Precipitation Climatology for Every Month and the Total Year from Rain-Gauges built on GTS-based and Historic Data, doi:10.5676/DWD_GPCC/CLIM_M_V2011_050, $2011 \mathrm{~b}$.

Meyer-Christoffer, A., Becker, A., Finger, P., Rudolf, B., Schneider, U., and Ziese, M.: GPCC Climatology Version 2011 at $1.0^{\circ}$ : Monthly Land-Surface Precipitation Climatology for Every Month and the Total Year from Rain-Gauges built on GTS-based and Historic Data, doi:10.5676/DWD_GPCC/CLIM_M_V2011_100, 2011c.

Meyer-Christoffer, A., Becker, A., Finger, P., Rudolf, B., Schneider, U., and Ziese, M.: GPCC Climatology Version 2011 at $2.5^{\circ}$ : Monthly Land-Surface Precipitation Climatology for Every Month and the Total Year from Rain-Gauges built on GTS-based and Historic Data, doi:10.5676/DWD_GPCC/CLIM_M_V2011_250, 2011d.

Miller, R. D.: The jackknife - a review, Biometrika, 61, 1-15, 1974.

Mitchel, T. D. and Jones, P. D.: An Improved Method of Construction a Database of Monthly Climate Observations and Associated High-Resolution Grids, Int. J. Climatol., 25, 693-712, 2005.

NCDC: Data Documentation for Dataset 9813: Daily and Subdaily Precipitation for the Former USSR, Version 1.0, National Climatic Data Center, 151 Patton Ave., Asheville, NC 288015001 USA, ftp://ftp.ncdc.noaa.gov/pub/data/documentlibrary/ tddoc/td9813.pdf (last access: 11 January 2013), 2005.

New, M. G., Hulme, M., and Jones, P. D.: Representing twentiethcentury space-time climate variability. Part I: development of a 1961-90 mean monthly terrestrial climatology, J. Climate, 12, 829-856, 1999.

New, M. G., Hulme, M., and Jones, P. D.: Representing twentiethcentury space-time climate variability. Part II: development of 1901-1996 monthly grids of terrestrial surface climate, J. Climate, 13, 2217-2238, 2000.

New, M., Todd, M., Hulme, M., and Jones, P.: Precipitation measurements and trends on the twentieth century, Int. J. Climatol., 21, 1899-1922, 2001.

New, M., Lister, D., Hulme, M., and Makin, I.: A high-resolution data set of surface climate over global land areas, Clim. Res., 21, 1-25, doi:10.3354/cr021001, 2002.

Nicholson, S. E.: Revised rainfall series for the West African subtropics, Mon. Weather Rev., 107, 620-623, 1979.

Nicholson, S. E.: The spatial coherence of African rainfall anomalies: Interhemispheric teleconnections, J. Clim. Appl. Meteorol., 25, 1365-1381, 1986.

Nicolson, S. E.: An overview of African rainfall fluctuations of the last decade, J. Climate, 6, 1463-1466, 1993.

Nicolson, S. E.: The intensity, location and structure of the tropical rainbelt over West Africa as a factor in interannual variability, Int. J. Climatol., 28, 1775-1785, 2008.

Oldenborgh, G., van Urk, A., and Allen, M.: The Absence of a Role of Climate Change in the 2011 Thailand Floods, in: Explaining Extreme Events of 2011 from a Climate Perspective, edited by: Peterson, T. C., Stott, P. A., and Herring, S., B. Am. Meteorol. Soc., 93, 1041-1067, 2012.
Parker, D. E., Hilburn, K., Hennon, P., and Becker, A.: Global Climate Precipitation, in: State of the Climate in 2011, B. Am. Meteorol. Soc., 93, 26-27, 2012.

Peterson, T. C. and Vose, R. S.: An overview of the Global Historical Climatology Network temperature database, B. Am. Meteorol. Soc., 78, 2837-2849, 1997.

Peterson, T. C., Vose, R., Schmoyer, R., and Razuvaev, V.: Global Historical Climatology Network (GHCN) quality control of monthly temperature data, Int. J. Climatol., 18, 1169-1179, 1998.

Rajeevan, M., Bhate, J., Kale, J. D., and Lal, B.: Development of a High Resolution Daily Gridded Rainfall Data for the Indian Region, Met. Monograph Climatology No. 22/2005, http://apdrc. soest.hawaii.edu/doc/india_rain_ref_report.pdf (last access: 11 January 2013), 2005.

Rubel, F. and Hantel, M.: BALTEX 1/6 degree daily precipitation climatology 1996-1998, Meteorol. Atmos. Phys., 77, 155-166, 2001.

Rubel, F. and Kottek, M.: Observed and projected climate shifts 1901-2100 depicted by world maps of the KöppenGeiger climate classification, Meteorol. Z., 19, 135-141, doi:10.1127/0941-2948/2010/0430, 2010.

Rubel, F. and Rudolf, B.: Global daily precipitation estimates proved over the European Alps, Meteorol. Z., 10, 403-414, 2001.

Rudolf, B.: The global precipitation climatology centre, WMO Bulletin, 44, 77-78, 1995.

Rudolf, B. and Rubel, F.: Global Precipitation. Chapter 11 in Hantel: Observed Global Climate, Landolt-Börnstein (Numerical Data and Functional Relationships), Group V: Geophysics, Volume 6, Springer Berlin Heidelberg New York, Springer Berlin Heidelberg New York, ISBN-13 978-3-540-20206-6, 11-22, 2005.

Rudolf, B. und Schneider, U.: Calculation of Gridded Precipitation Data for the Global Land-Surface using in-situ Gauge Observations, Proceedings of the 2nd Workshop of the International Precipitation Working Group IPWG, Monterey, October 2004, ISBN 92-9110-070-6, ISSN 1727-432X, 231-247, 2005.

Rudolf, B., Hauschild, H., Reiss, M., and Schneider, U.: Berechnung der Gebietsniederschläge im 2,5 ${ }^{\circ}$-Raster durch ein objektives Analyseverfahren, Meteorol. Z., 1, 32-50, 1992.

Rudolf, B., Hauschild, H., Rueth, W., and Schneider, U.: Terrestrial precipitation analysis: Operational method and required density of point measurements, in: Global Precipitation and Climate Change, edited by: Desbois, M. und Desalmand, F., Springer, Berlin, 173-186, 1994.

Rustemeier, E., Kapala, A., Mächel, H., Meyer-Christoffer, A., Schneider, U., Ziese, M., Venema,V., Becker, A., and Simmer, C.: An automatic method to homogenize trends in longterm monthly precipitation series, Geophys. Res. Abstr., Vol. 14, EGU2012-10654, 2012.

Schneider, U., Henning, D., Hauschild, H., Reiss, M., and Rudolf, B.: Zur Berechnung monatlicher Niederschlagshöhen aus synoptischen Meldungen, Meteorol. Z., 1, 22-31, 1992.

Schneider, U., Becker, A., Finger, P., Meyer-Christoffer, A., Rudolf, B., and Ziese, M.: GPCC Monitoring Product Version 4.0 at $1.0^{\circ}$ : Near Real-Time Monthly Land-Surface Precipitation from Rain-Gauges based on SYNOP and CLIMAT Data, doi:10.5676/DWD_GPCC/MP_M_V4_100, 2011a. 
Schneider, U., Becker, A., Finger, P., Meyer-Christoffer, A., Rudolf, B., and Ziese, M.: GPCC Monitoring Product Version 4.0 at $2.5^{\circ}$ : Near Real-Time Monthly Land-Surface Precipitation from Rain-Gauges based on SYNOP and CLIMAT Data, doi:10.5676/DWD_GPCC/MP_M_V4_250, 2011b.

Schneider, U., Becker, A., Finger, P., Meyer-Christoffer, A., Rudolf, B., and Ziese, M.: GPCC Full Data Reanalysis Version 6.0 at $0.5^{\circ}$ : Monthly Land-Surface Precipitation from Rain-Gauges built on GTS-based and Historic Data, doi:10.5676/DWD_GPCC/FD_M_V6_050, 2011c.

Schneider, U., Becker, A., Finger, P., Meyer-Christoffer, A., Rudolf, B., and Ziese, M.: GPCC Full Data Reanalysis Version 6.0 at $1.0^{\circ}$ : Monthly Land-Surface Precipitation from Rain-Gauges built on GTS-based and Historic Data, doi:10.5676/DWD_GPCC/FD_M_V6_100, 2011d.

Schneider, U., Becker, A., Finger, P., Meyer-Christoffer, A., Rudolf, B., and Ziese, M.: GPCC Full Data Reanalysis Version 6.0 at $2.5^{\circ}$ : Monthly Land-Surface Precipitation from Rain-Gauges built on GTS-based and Historic Data, doi:10.5676/DWD_GPCC/FD_M_V6_250, 2011e.

Schneider, U., Becker, A., Finger, F., Meyer-Christoffer, A., Ziese, M., and Rudolf, B.: GPCC's new land-surface precipitation climatology based on quality-controlled in-situ data and its role in quantifying the global water cycle, Theor. Appl. Climatol., accepted, 2013.

Schulzweida, U., Kornblueh, L., and Quast, R.: Climate Data Operators (CDO), User Guide, Version 1.5.2, https://code.zmaw. de/files/cdo/html/1.5.2/cdo.pdf (last access: 11 January 2013), 2011.

Sen, P. K.: Estimates of the regression coefficient based on Kendall's tau, J. Am. Stat. Assoc., 63, 1379-1389, 1968.

Shepard, D.: A two-dimensional interpolation function for irregularly spaced data, Proc. 23rd ACM Nat. Conf., Brandon/Systems Press, Princeton, NJ, 517-524, 1968.

Simmons, A.: From observations to service delivery: Challenges and opportunities, WMO Bulletin, 60, 96-107, 2011.

Simmons, A. J., Willet, K. M., Jones, P. D., Thorne P. W., and Dee, D. P.: Low frequency variations in surface atmospheric humidity, temperature, and precipitation: Inferences from reanalyses and monthly gridded observational data sets, J. Geophys. Res., 115, D01110, doi:10.1029/2009JD012442, 2010.

Strangeways, I.: Precipitation: Theory, Measurement and Distribution, Cambridge University Press, Cambridge, 290 pp., 2007.

Trenberth, K. E.: The Definition of El Niño, B. Am. Meteorol. Soc., 78, 2771-2777, 1997.

UCL: http://drought.mssl.ucl.ac.uk/sources.html (last access: 11 January 2013), 2011.

USGS: Global 30 Arc-Second Elevation (GTOPO 30), http://eros. usgs.gov/\#/Find_Data/Products_and_Data_Available/gtopo30/, last access: 11 January 2013.
Wild, M., Grieser, J., and Schär, C.: Combined surface solar brightening and increasing greenhouse effect support recent intensification of the global land-based hydrological cycle, Geophys. Res. Lett., 35, L17706, doi:10.1029/2008GL034842, 2008.

Willmott, C. J., Rowe, C. M., and Philpot,W. D.: Small-scale climate maps: A sensitivity analysis of some common assumptions associated with grid-point interpolation and contouring, Am. Cartographer, 12, 5-16, 1985.

WMO: Review of requirements for area-averaged precipitation data, surface based and space based estimation techniques, space and time sampling, accuracy and error, data exchange, WCP-100, WMO/TD-No. 115, 1985.

WMO: The Global Precipitation Climatology Project - Implementation and Data Management Plan, WMO/TD-No. 367, 47 pp. and 6 Appendices, Geneva, 1990.

WMO: WMO Publication No. 9, Volume A, Observing Stations and WMO Catalogue of Radiosondes, http://www.wmo.int/pages/ prog/www/ois/volume-a/vola-home.htm, last access: 8 November 2011a.

WMO: WMO statement on the status of the global climate in 2010, WMO No. 1074, http://www.wmo.int/pages/ publications/showcase/documents/1074_en.pdf (last access: 11 January 2013), 2011b.

Xie, P. and Arkin, P. A.: Global Precipitation: a 17-year monthly analysis based on gauge observations, satellite estimates, and numerical model outputs, B. Am. Meteorol. Soc., 78, 2539-2558, 1997.

Xie, P., Rudolf, B., Schneider, U., and Arkin, P. A.: GaugeBased Monthly Analyses of Global Land Precipitation from 1971 to 1994, J. Geophys. Res., 101, 19023-19034, doi:10.1029/96JD01553, 1996.

Yatagai, A., Arakawa, O., Kamiguchi, K., Kawamoto, H., Nodzu, M. I., and Hamada, A.: A 44-year daily gridded precipitation dataset for Asia based on a dense network of rain gauges, SOLA, 5, 137-140, doi:10.2151/sola.2009-035, 2009.

Yatagai, A., Kamiguchi, K., Arakawa, O., Hamada, A., Yasutomi, N., and Kitoh, A.: APHRODITE: Constructing a Long-term Daily Gridded Precipitation Dataset for Asia based on a Dense Network of Rain Gauges, B. Am. Meteorol. Soc., 93, 1401-1415, doi:10.1175/BAMS-D-11-00122.1, 2012.

Ye, B., Yang, D., Ding, Y., Han, T., and Koike, T.: A bias-corrected precipitation climatology for China, J. Hydrometeorol., 5, 11471160, 2004.

Ziese, M., Becker, A., Finger, P., Meyer-Christoffer, A., Rudolf, B., and Schneider, U.: GPCC First Guess Product at 1.0 $0^{\circ}$ Near Real-Time First Guess Monthly Land-Surface Precipitation from Rain-Gauges based on SYNOP Data, doi:10.5676/DWD_GPCC/FG_M_100, 2011. 